EPJ Web of Conferences 104, 01001 (2015)

DOI: $10.1051 /$ epjconf/201510401001

(C) Owned by the authors, published by EDP Sciences, 2015

\title{
Neutrons for industry
}

\author{
Winfried Petry \\ Heinz Maier-Leibnitz Zentrum (MLZ), Technische Universität München, Garching, Germany
}

\section{Introduction}

Basic science with neutrons should be and certainly is curiosity driven. It is the uncommitted willingness of the scientist to explore the laws of nature beyond the already known which creates true innovation. Beyond this appraisal of western scientific culture there is ample of space and also a great need for the eventual transfer of innovation to products which may serve for the wealth of our society. This process asks for intense interaction between science and industry, i.e. researchers and engineers. Speaking with the language of engineers this process is classified in Technology Readiness Levels (TRL) to assess the maturity of evolving technologies during its development and are generally measured on a scale from 1 (basic technology research) to 9 (system test, launch \& operation).

Within the TRL-scale research with neutrons is dominantly located on the levels 1 to 3 , i.e. basic research to first principle feasibility. However there are important examples where research with neutrons goes far beyond. Tailoring crank shifts for engines by measuring completely nondestructive internal stresses on an atomic scale certainly involves levels 7 to 8 (subsystem development). Checking routinely turbine plates for aircrafts and gas turbines by neutron tomography even goes beyond technology levels 9 , i.e. manufactured products are routinely checked for quality. In some important cases neutrons are the means to produce materials modern society absolutely needs, i.e. most homogenously doped bulk silicon used in high voltage direct current electricity transport and hybrid cars. Radioisotopes such as ${ }^{131} \mathrm{I}, 99 \mathrm{mTc},{ }^{177} \mathrm{Lu}$ and ${ }^{161} \mathrm{~Tb}$ can only be produced on a large scale using high neutron fluencies.

- In a more systematic view industry uses neutron beams for

- basic research directly driven by urgent questions raising from industrial applications of work pieces or functional materials

- optimization of new materials with new/"better" functionalities

- characterization of materials, understand the relation materials properties - functionality

- product development

- production.

The uniqueness and often enough the superiority of neutrons for industrial applications with respect to other techniques lies in its ability to penetrate all kind of dense matter and at the same time to visualize with considerable contrast and sensitivity the different elements, magnetism, structures, segregation,

This is an Open Access article distributed under the terms of the Creative Commons Attribution License 4.0, which permits unrestricted use, distribution, and reproduction in any medium, provided the original work is properly cited. 


\section{EPJ Web of Conferences}

Table 1. Equivalence of energy, speed and wavelength for neutrons.

\begin{tabular}{|l|l|l|l|l|}
\hline & energy & temperature & velocity & wave length \\
\hline cold neutrons & $0.1-20 \mathrm{meV}$ & $25 \mathrm{mK}$ & $600 \mathrm{~m} / \mathrm{s}$ & $0,22,5 \mathrm{~nm}$ \\
\hline thermal neutrons & $3-150 \mathrm{meV}$ & $300 \mathrm{~K}$ & $2200 \mathrm{~m} / \mathrm{s}$ & $0,07-0,5 \mathrm{~nm}$ \\
\hline hot neutrons & $40-10^{3} \mathrm{meV}$ & $2000^{\circ} \mathrm{C}$ & $5000 \mathrm{~m} / \mathrm{s}$ & $0,028-0,14 \mathrm{~nm}$ \\
\hline epithermal neutrons & $10^{-3}-1 \mathrm{MeV}$ & & & \\
\hline fast/fission neutrons & $0.5-20 \mathrm{MeV}$ & & & \\
\hline
\end{tabular}

compounds, etc. on a scale ranging from sub-atomic distances to micrometers in objects which might be very small or very large. At the same time neutron scattering is able to reveal the dynamics of atoms, structures and magnetic moments, i.e. the internal motion of matter. For instance thermal neutrons (MeV range) easily penetrate $10 \mathrm{~cm}$ of massive steel and fast neutrons $(2 \mathrm{MeV})$ easily penetrate massive hydrogen storages. Complementary to X-rays thermal neutrons have a particular high contrast with the lightest element, hydrogen. Thereby thermal neutrons reveal the dynamics of proton conductors for fuel cell applications. Therefore neutrons ideally allow the combination of completely non-destructive and in-situ / in-operando characterization of work pieces.

\section{Neutron methods for industrial application}

There is a broad range how intense neutron beams or neutron fields can be used for industrial purposes. Free neutrons might be simply scattered by the atoms or the nuclei which they hit or induce a nuclear reaction. In the latter case the neutron is absorbed, the isotope/element transformed to another one and all kind of irradiation is created. The deposition of energy in the course of the nuclear reaction is far beyond of atomic and molecular binding energies causing defects and materials damage. Scattering applications need the consideration of neutrons as matter wave with wave-length in the order of atomic distances, therefore ideally suited to tell where the atoms are. These neutrons have thermal energies and are therefore sensitive probes for the internal motion of matter which itself is important for the functionality of materials. Radiography with neutrons combines both. The forward transmission through an object is determined by absorption, i.e. nuclear reaction and scattering processes.

Table 1 gives a glance on the different neutron energies used for industrial applications.

Fast or non-moderated fission neutrons have considerably different neutron cross sections for absorption as well as scattering. For instant hydrogen has a bond total cross section for thermal neutrons $\sigma_{\text {total,thermal }}=82$ barn whereas the same decreases for fast neutrons to $\sigma_{\text {total,fast }} \sim 2$ barn. For instance fast neutrons enable radiography and tomography of objects containing high degree of hydrogen like fuel cells or oil containing work pieces. Figure 1 nicely demonstrates the different mass attenuation coefficients for thermal and fast neutrons and compares with those of $\gamma$-rays of different energy. It also shows the prominent feature of thermal neutrons, namely huge contrast variations for neighboring elements or isotopes.

Fast neutrons impinging on solid matter cause displacement of atoms, i.e. radiation damage. This is of considerable importance for structural materials in nuclear technology. Materials Test Reactors (MTR) providing high fluences of fast neutrons are specialized to test the behavior of components for nuclear technology with respect to irradiation damage. In particular they provide the necessary cooling equipment to safely evaporate the generated heat during irradiation. This application of material testing is not considered here. Prominent materials testing reactors in Europe are BR 2 in Mol, Belgium or in future the Jules Horowitz Reactor at CEA-Cadarache, France. Further external beams of fast neutrons are ideally suited to simulate the bombardment of electronics in space by all kind of cosmic radiation [4-6].

Thermal neutrons serve industrial needs in several respect: i) Thermal neutron capture produces radioisotopes which are used for tracer experiments, as radiation sources in industry, or most 


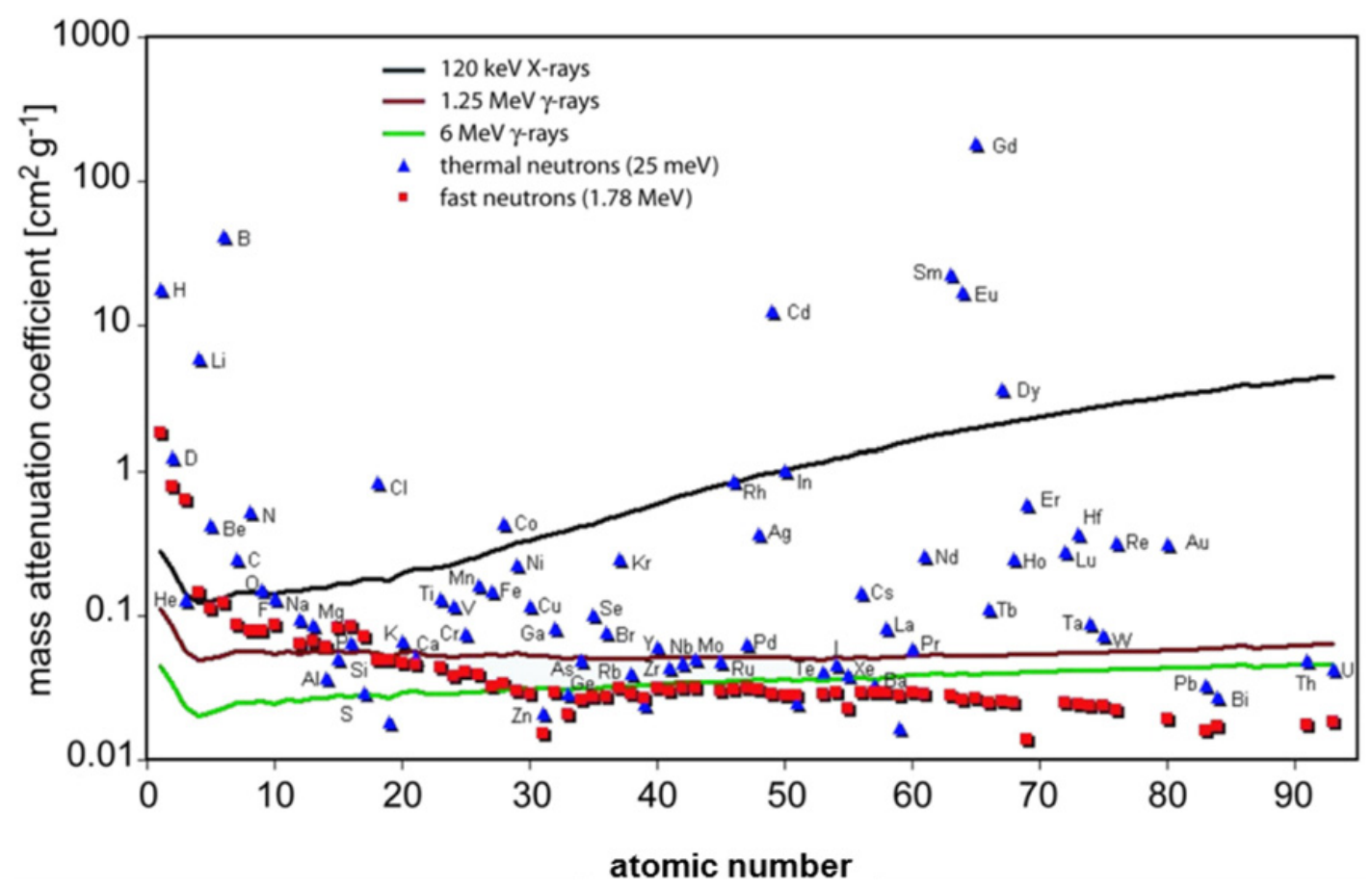

Figure 1. Bob-bond Mass attenuation coefficient for thermal and fast neutrons, compared to those for $\gamma$-rays of different energy [1, 2]. Data are from NEA database [3] and are related to the non-bond cross section, which is appropriate for $2 \mathrm{MeV}$ fission neutrons. In most cases for thermal neutron application the atoms have to be considered as bond and the bond cross sections is appropriate, $\sigma$ bond $=((\mathrm{A}+1) / \mathrm{A}) 2 \sigma \mathrm{free}$.

prominently for nuclear medicine. ii) The radioactive decay of the excited nuclei created by thermal neutron capture is characteristic for the initial nuclei and element. The concentration is determined from the measurement of the intensitiy of the characteristic radiation which is emitted with delay after the $\mathrm{n}$-capture reaction. Neutron activation analysis (NAA) is one of the most sensitive methods to detect ppb to ppt elemental concentrations - Fig. 2 - without any preceding chemical treatment and is often used as standard for chemical concentration measurements [7, 8]. iii) Different to NAA prompt $\gamma$ activation analysis (PGAA) uses the prompt decay of nuclei excited by thermal neutron capture and is in particular sensitive to light elements ( $\mathrm{H}, \mathrm{Li}, \mathrm{B}, \mathrm{Na}, \mathrm{Mg}, \mathrm{Al}, \mathrm{Si}, \mathrm{S}, \mathrm{Cl}, \ldots$ ) - see Fig. 3 [9-11]. iv) Further thermal neutrons may transmute a stable element to another stable element by nuclear reaction, i.e. doping by neutron transmutation. v) Like fast neutrons but with considerable different contrast variation between the isotopes/elements thermal neutrons penetrate easily massive bulk materials like $\mathrm{Al}, \mathrm{Fe}$ or $\mathrm{Pb}$. Neutron radiography and tomography makes the invisible visible for all kind of complex materials and work pieces. vi) Last not least scattering of neutrons ranging from hot to cold neutrons tells us where the atoms are, how they move and reveal the magnetic properties of matter.

There are a few industrial applications of neutrons based on small and movable neutron generators as they are for instance realized by the acceleration of $\mathrm{D}$ on $\mathrm{T}$ (in solid solution), creating $14.4 \mathrm{MeV}$ fast neutrons which are eventually thermalized by a moderator like polyethylen. PGAA or NAA is then used to analyze the elemental composition of any raw material flow for further adaption to the following manufacturing process. With the high penetrating power of thermal neutrons and incase of PGAA the sensitivity for light elements this kind of analysis is particularly well suited for on-line real-time measurement. A typical costumer is the cement industry which needs a continuous chemical analysis of 


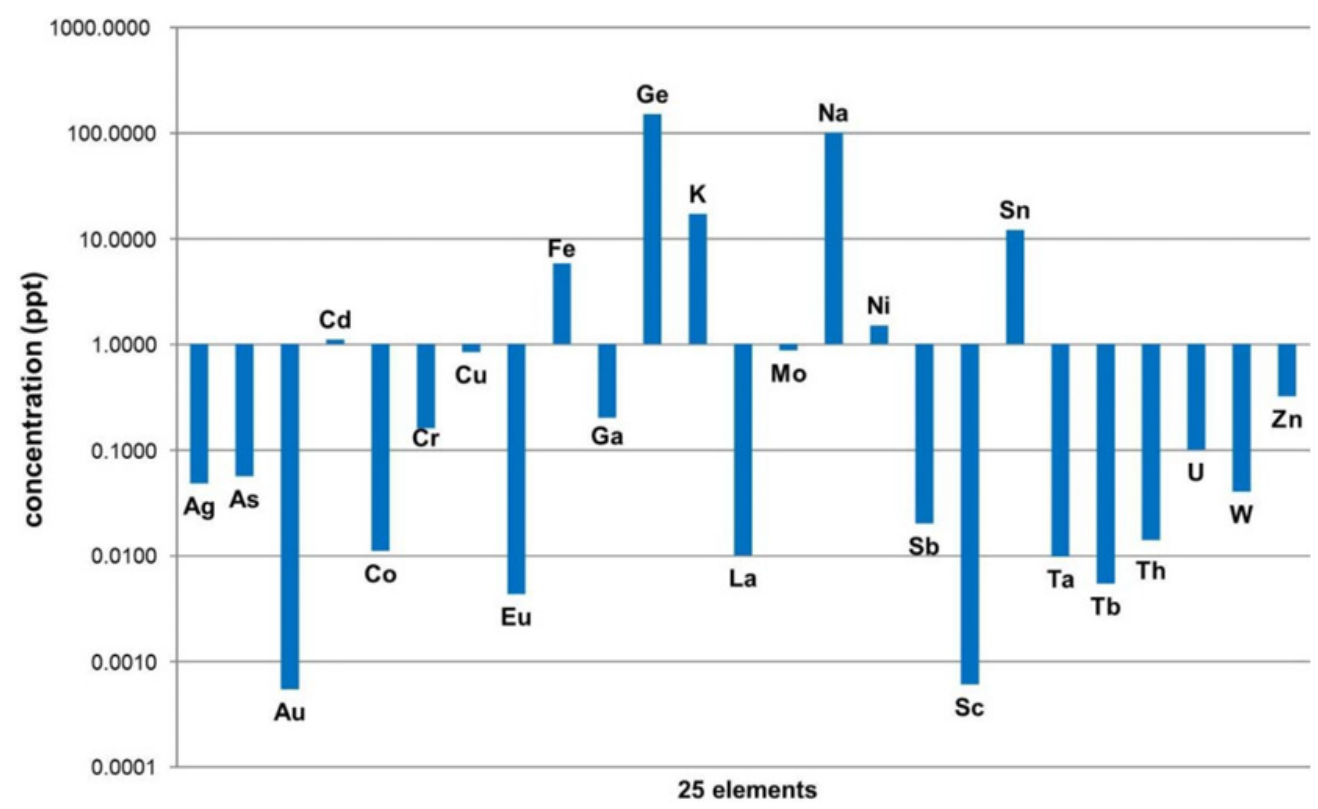

Figure 2. Limits of detection of trace elements in Silicon by NAA [7].

the incoming raw material flow. Here the measuring device is installed between the first crusher and the pre-homogenization stockpile, or before the raw mill for the blending of the raw mix. Controlling the raw materials makes it possible to optimize the composition of the mix before the kiln operations. Other applications are in the mining industry, thermal power plants and waste treatment plants $[12,13]$.

Europe has a reasonable variety in neutron sources. The HFR of the Institute Laue Langevin is certainly the international flagship with respect to available neutron flux and suite of scattering instruments. National sources with considerable international user base like the MLZ at Garching, ISIS at Rutherford Appleton laboratory near Oxford, ORPHÉE at CEA-Saclay, SINQ at PSI, or BER 2 at HZB have instrumentation of similar quality and often address more particular the industrial user. In a similar way smaller neutron sources like Budapest Neutron Centre in Hungary or the research reactor LVR-15 at Rez, Czech Republic have specialized instrumentation for industrial usage.

A common scheme for this industry near application of research with neutrons is its orientation along the grand technological challenges of modern society: energy, information and communication, health and life, key technologies, earth, environment and cultural heritage.

The neutron research source FRM II [14] together with the Heinz Maier-Leibnitz Zentrum [15] in Garching, Germany provides brilliant external beams of fast, hot, thermal and cold neutrons and irradiation facilities in the heavy water moderator. About $30 \%$ of its usable neutron flux is dedicated to industrial usage or research which serves industrial needs. Some of this is even used for industrial production. Most of the following examples but not exclusively stem from work done at FRM II and MLZ. They might elucidate how neutrons serve industrial needs.

\section{Homogenous doping for power electronics}

Pure silicon is a very poor conductor of electricity. However, it is industrially viable for semiconductors when it contains a small amount of impurities which are either electron (such as phosphorus) or hole conductors. Usually this happens by deposition or ion implantation of theses dopants followed by diffusion processes. Spatially these processes are controlled in the 10 nanometer range for today's 


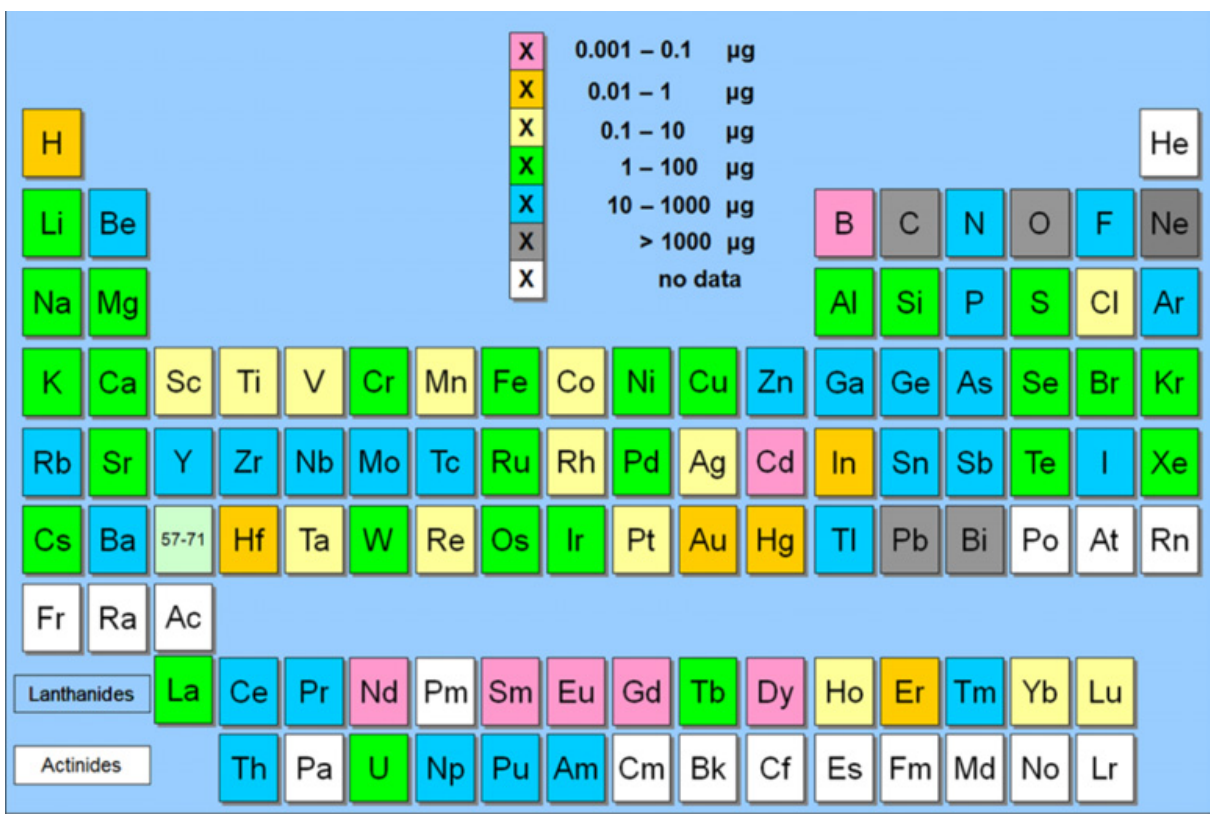

Figure 3. Sensitivity of PGAA for the elements [9]. Shown are estimated limits for the detection of traces as given for the instrument PGAA at MLZ. These limits also depend on the matrix material.

microelectronics. However, for high power switching devices like tyristors or transistors extreme homogeneity of this doping over some $10 \mathrm{~cm}$ is asked for. This is by far best achieved by silicon transmutation - see Fig. 4. The silicon isotope ${ }^{30} \mathrm{Si}$ (natural abundance of $3.1 \%$ ) is activated during irradiation by the capture of thermal neutrons $(25 \mathrm{meV})$ with a cross section $\sigma_{\mathrm{abs}}=0.107(2)$ barn and is converted, with a half-life of 2.6 hours, into stable ${ }^{31} \mathrm{P}$. Technically this is achieved by exposing large silicon single crystals to an intense field of thermal neutrons near or in between the fuel assembly. In case this neutron field is homogenous in distribution the so-called neutron transmutation doping (NTD) guarantees a particularly homogeneous P-distribution in the silicon crystal.

At the research neutron source silicon crystals with a maximum height of $50 \mathrm{~cm}$ and a diameter of $20 \mathrm{~cm}$ are placed in the irradiation position, situated in the heavy water moderator and subjected to a well-defined thermal neutron flux [16]. To achieve a homogeneous doping, the neutron flux is smoothed in the irradiation position of the SDA by a suitable nickel coating and, in addition, the basket is rotated about its own cylinder axis during irradiation. In most cases the Si doping channel is situated within the fuel assembly, i.e. the silicon is exposed to thermal and fast neutrons of roughly equal intensity. Fast neutrons have a considerable lower cross section for the doping reaction and in addition create defects in the crystal. The latter affects the electronic properties of the doped silicon and is not desired. At FRM II the silicon doping position is $1 \mathrm{~m}$ (center to center) away from the single compact core in the heavy water moderator, thereby guarantying a suppression of the fast flux by a factor $>1000[16,17]$. This excellent suppression of fast neutrons makes it possible to produce high resistivity doping. The demand for doped silicon by neutron irradiation is so high that, at the FRM II, up to 15 tons are commissioned annually by companies from Europe and Asia. Typical specific resistivity of the silicon crystals after irradiation is in the range of 25 to $1000 \Omega \mathrm{cm}$.

Silicon doping is a purely commercial production facility at the FRM II. Si doped at FRM II is instrumental for renewable energy supply, for example for high-power electronics such as long-range DC power transmission, or in hybrid vehicles. 

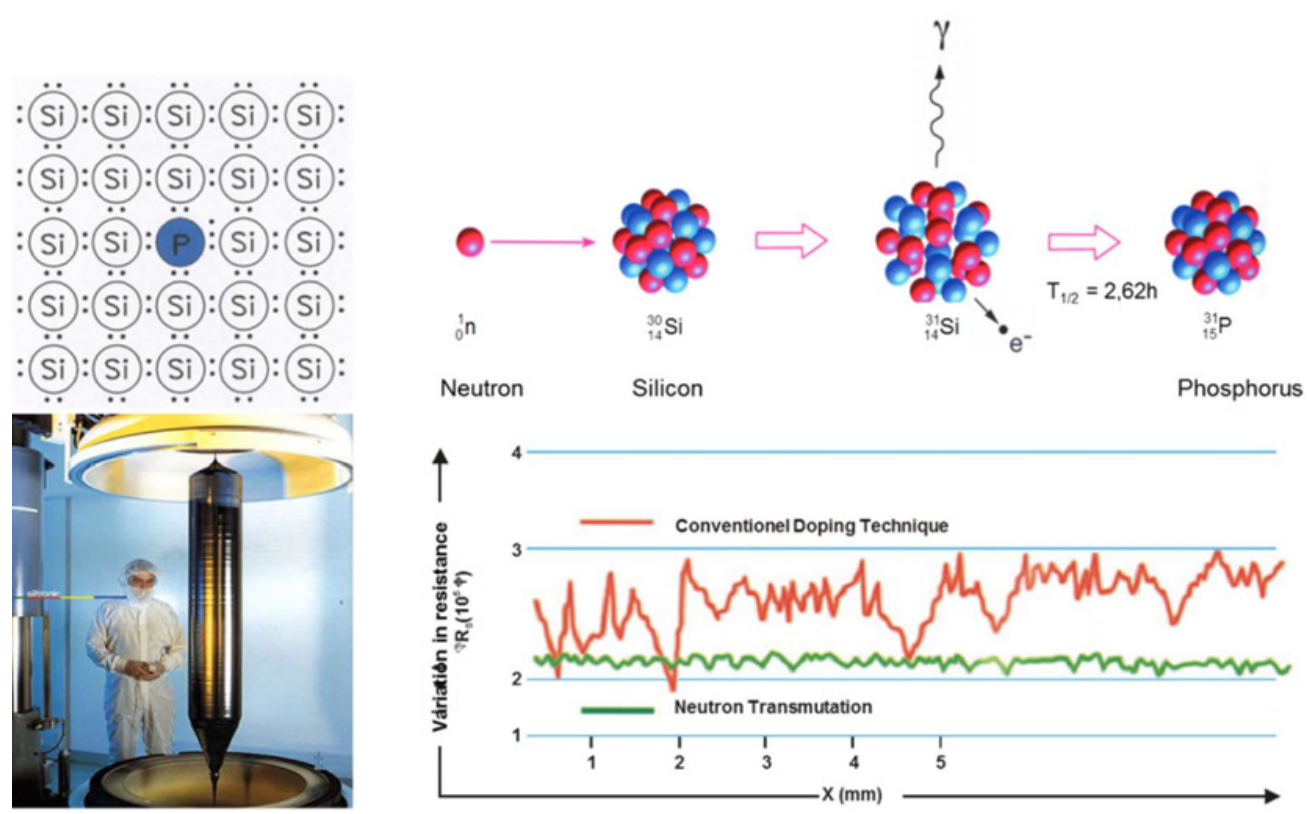

Figure 4. Scheme of Si transmutation doping. Top right: Nuclear reaction, ending with a stable ${ }^{31} \mathrm{P}$ Isotope. Top left: $\mathrm{P}$ is incorporated in $\mathrm{Si}$ at a regular lattice site and acts as electron donator. Bottom right: Comparison of the resistivity of a conventional doped and neutron transmutation doped waver along the surface of the waver. The superiority of transmutation doping with respect to homogeneity of the resistivity is clearly visible.

In standard silicon solar modules, the costs of silicon wafers make up 50\% of the total costs. One reason is the high costs for near-semiconductor quality feedstock with $7 \mathrm{~N}$ to $8 \mathrm{~N}$ purities, as purification steps are time and resource consuming. Low-cost silicon, such as metallurgical grade (MG) and upgraded metallurgical grade (UMG) silicon with purities of approximately 2-3 N and 3-5 N could be used for new solar cell concepts. One of the crucial problems is the high amount of metallic impurities, for example $\mathrm{Fe}$ or $\mathrm{Cr}$. These contaminations degrade the minority carrier lifetime and therefore the solar cell efficiency by forming recombination centers. The cell efficiency is less affected by metals in precipitates than by interstitial impurities even at lower densities. Nevertheless, starting with MG silicon, it is still important to reduce the overall concentration of transition metal impurities.

NAA is well-suited for the detection of transition metals in solar grade silicon. In a case study it was shown that the metals of interest, such as $\mathrm{Cr}$, Mn, and Fe, could be detected by NAA, from less than $\mathrm{ng} / \mathrm{g}$ to $\mathrm{mg} / \mathrm{g}$. The sample preparation consisted of only one surface cleaning step and the risk of contamination was much lower compared to other analyses because the silicon does not have to be dissolved before analysis. To accelerate the detection of transition metals locally scanning whole vertical silicon columns were accomplished, demonstrating that it is a viable method for industrial application [18].

\section{How to get the hydrogen into the tank}

Storing hydrogen safely and efficiently is one of the main technological barriers preventing the widespread adoption of hydrogen as an energy carrier and the subsequent transition to a so-called "hydrogen economy". Direct bounding of $\mathrm{H}$ in transition metal hydrides has been studied to a large extent in the past and is a today's industrial solution. Inherent limitations are the upper limit of $2 \mathrm{wt} \%$ $\mathrm{H}_{2}$ storage capacity and incomplete hydrogen release during unloading. To overcome these limitations, the search for new solid state storage materials attracts a significant amount of attention. Among the 
Table 2. Hydrogen storage capacity and reaction enthalpy for some complex hydride systems (by courtesy W. Lohstroh).

\begin{tabular}{|c|c|c|c|}
\hline Reaction & wt \% H2 & $\Delta \mathbf{H}\left[\mathrm{kJmol}-1 \mathbf{H}_{2}\right]$ & \\
\hline $\mathrm{MgH}_{2} \leftrightarrow \mathrm{Mg}+\mathrm{H}_{2}$ & 7.6 & 74.5 & [19] \\
\hline $\mathrm{NaAlH}_{4} \leftrightarrow 1 / 3 \mathrm{Na}_{3} \mathrm{AlH} 6+2 / 3 \mathrm{Al}+\mathrm{H}_{2}$ & 3.7 & 38 & [20] \\
\hline $\mathrm{Na}_{3} \mathrm{AlH}_{6} \leftrightarrow 3 \mathrm{NaH}+\mathrm{Al}+3 / 2 \mathrm{H}_{2}$ & 1.5 & 47 & [20] \\
\hline $\mathrm{LiBH}_{4} \leftrightarrow \mathrm{LiH}+\mathrm{B}+3 / 2 \mathrm{H}_{2}$ & 13.9 & 74 & [21] \\
\hline $\mathrm{NaBH}_{4} \leftrightarrow \mathrm{NaH}+\mathrm{B}+3 / 2 \mathrm{H}_{2}$ & 8.0 & 135 & [22] \\
\hline $\mathrm{Mg}\left(\mathrm{BH}_{4}\right) \leftrightarrow \mathrm{MgB}_{2}+2 \mathrm{H}_{2}$ & 14.9 & $\sim 40-50$ & {$[23,24]$} \\
\hline $\mathrm{Mg}\left(\mathrm{NH}_{2}\right)_{2}+2 \mathrm{LiH} \leftrightarrow \mathrm{Li}_{2} \mathrm{Mg}(\mathrm{NH})_{2}$ & 5.6 & 39 & [25] \\
\hline
\end{tabular}

most attractive solutions are physisorption of $\mathrm{H}_{2}$ molecules on porous, high surface area materials and chemisorption in non-classical hydrids.

Neutrons with their privileged contrast for hydrogen or deuterium play a great role in elucidating atomic and molecular processes for physi- and chemisorption, but also shed light on the technological processes happening in operando when charging and unloading hydrogen tanks.

Table 2 nominates some of the most promising candidates for chemisorption in complex hydrides. Questions tackled in the corresponding neutron experiments are the chemical reaction and its intermediates, catalytic acceleration of the reaction, the atomistic diffusion process, where sits the hydrogen, how does it diffuse, excitations of the bond hydrogen complex in order to understand the thermodynamics of charging and unloading the storage. Difficulties to overcome are reproducibility and aging, heat dissipation, time scales for charging and unloading, approaching ambient conditions for pressure and temperature during operation. In-situ and in-operando neutron diffraction is widely used, accompanied by quasielastic neutron scattering revealing diffusion mechanisms and rotational excitations [26-30].

Complex hydrides are very stable hydrogen storage materials with high binding enthalpies and charging and unloading most often require elevated temperature and pressure conditions. Physisorption of hydrogen shows opposite properties, low binding enthalpies $\Delta \mathrm{H}$, with for practical purposes often uncontrolled release of the hydrogen. Porous materials with high surface areas are a promising approach and the storage capacity can reach $7-10 \mathrm{wt} \% \mathrm{H}_{2}$. To enhance the binding enthalpy, metal-organic framework (MOF) compounds with exposed metal sites are intensely investigated, which interact more strongly with physisorbed hydrogen molecules. Some of the MOFs are designed in a way that they also can store $\mathrm{CO}_{2}$, i.e. are candidates for the sequestration of greenhouse emission gases. Quasielastic and inelastic neutron scattering on such systems contributes to the understanding of the different binding sites by measuring vibrational excitations, ascribed to the different physisorbing sites [31-34].

In parallel to the ongoing research for materials with optimized $\Delta \mathrm{H}$ industry tests real $\mathrm{H}_{2}$ storages with new materials based on chemi- or physisorption. Only fast neutrons as available at MLZ are able to penetrate through pressure tanks including the H-storing material. A lightweight tank for hydrogen storage developed during the European project NESSHY and filled with $4 \mathrm{~kg}$ of sodium alanate $\left(\mathrm{NaAlH}_{4}\right)$ was tested. The sodium alanate was doped with $\mathrm{TiCl}_{3} / \mathrm{AlCl}_{3}$ and expanded graphite and then compacted to pellets. Pellets have several advantages that enhance the efficiency of the tank. Their porosity is lower than that of loose powder, thus increasing the volumetric capacity but also gravimetric capacity. The tank was analyzed after 33 hydrogen loading / unloading cycles via neutron radiography at NECTAR. Measuring time for a single radiography took $60 \mathrm{~s}$, perfectly adapted to follow the kinetics of the slow loading/un-loading cycle of about $2 \mathrm{~h}$. The radiography - see Fig. 5 - revealed the mechanical stability of the pellets when compared to the powder filling and the distribution of the hydrogen. An improvement in gravimetric capacity of $83 \%$ and $49 \%$ in volumetric capacity compared to previous experiments was achieved. Heat evolution and temperature spikes during hydrogen absorption were studied. Due to the high specific heat of the complex hydride, the storage material itself acts as a heat sink, aiding in the heat management of the system. 

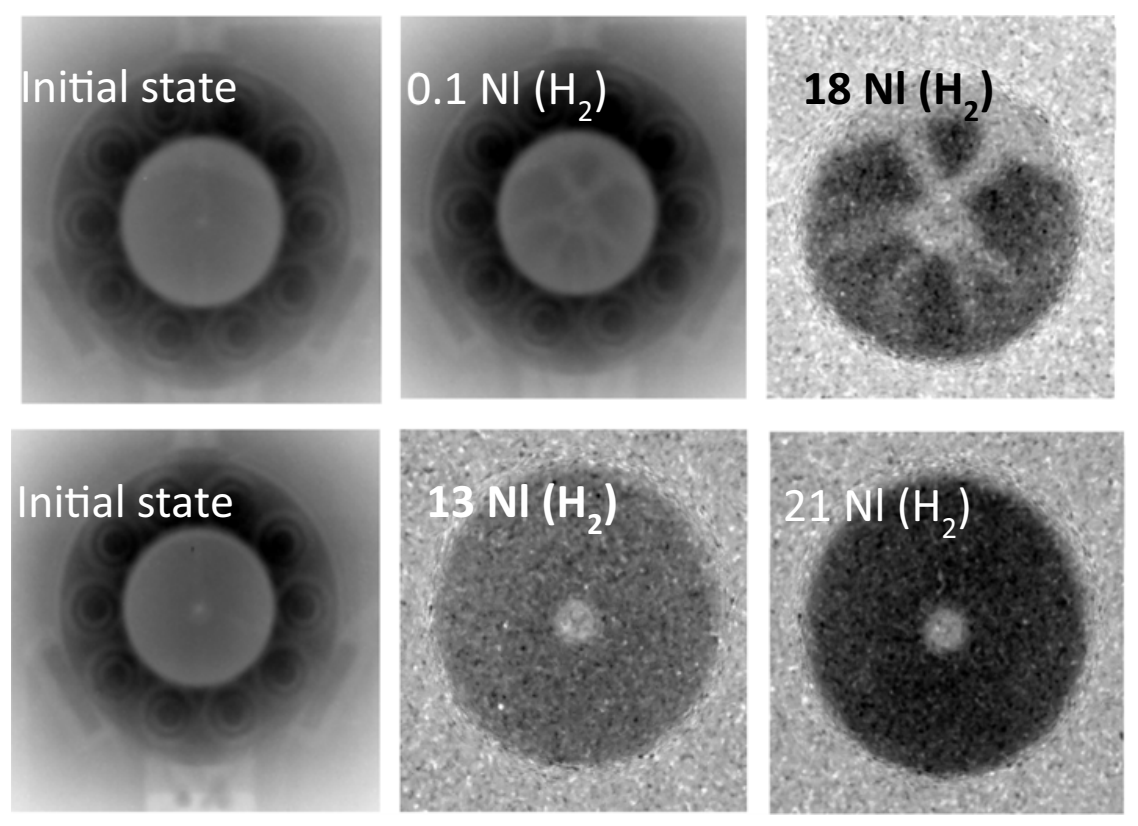

Figure 5. Radiographies of hydrogen absorption of $\mathrm{NaH}+\mathrm{Al}+0.05 \mathrm{TiCl}_{3}$ in a steel tank at hydrogen filling levels, $\mathrm{NI}=$ norm liter filling of $\mathrm{H}_{2}$. Top: filling with $30 \mathrm{~g}$ of $\mathrm{NaH}+\mathrm{Al}+0.05 \mathrm{TiCl}_{3}$ powder. The powder structure changes immediately after pressure application resulting in a radial channel structure (hydrogen inlet from the center). Bottom: filling with $50 \mathrm{~g}$ of $\mathrm{NaH}+\mathrm{Al}+0.0 \mathrm{TiCl}_{3}$ compressed to a pellet. The pellet structure remains macroscopically stable also after many cycles (by courtesy S. Börries).

For applications where a relatively slow charging of the tank $(2 \mathrm{~h})$ is permissible, as for stationary large scale storages, hydrogen solid-state storage is an interesting alternative due to its low pressure operation and binding of the hydrogen in a safe chemical form [35-37].

\section{Batteries inside}

Li-ion batteries are considered as the major energy storage technology in the field of portable electronics and electric vehicles. Boosted by the progress for these applications they are meanwhile also considered as local storage for excess electricity. Particularly the applications in electro mobility demand for rechargeable batteries with higher energy, improved output power, lower weight and less costs. These performance parameters are determined by numerous degrees of freedom, from chemical and structural details of the used materials up to the cell design and processing. Optimization of such complicated electrochemical devices requires "live" information about the processes occurring inside the cell on atomic/molecular as well as on macroscopic scale of $\mu$ - to millimeter and on time scales imaging the kinetics of charging and discharging. This calls for new dedicated experimental techniques, which are non-destructive and capable to study complete operational cells without a need to disassemble them. Hereby the risks of material oxidation, electrolyte evaporation or uncontrolled changes of the state of charge that can occur upon cell opening are avoided. Thanks to the peculiar features of the neutrons to localize light atoms as lithium, hydrogen or oxygen, to distinguish between different isotopes, the high penetration depth and the nearly constant neutron form factor for diffraction they are a non-alternative and non-destructive tool for probing the complex electrochemistry in operando. Here the full breath of neutron techniques comes to application, such as prompt $\gamma$-activation analysis for accurate elemental analysis of the light atoms, radiography and tomography for 3-D mapping of the Li distribution, small 


\section{Polychromatic beam}

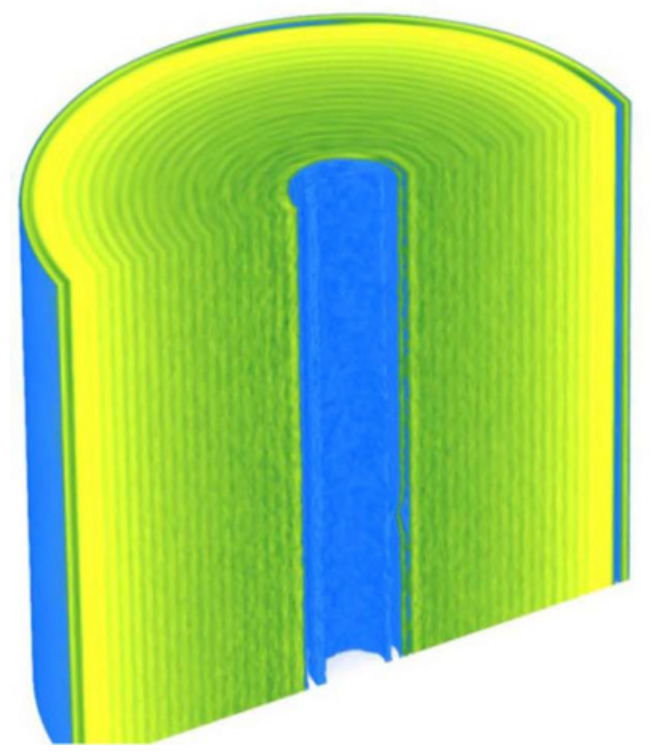

Monochromatic beam

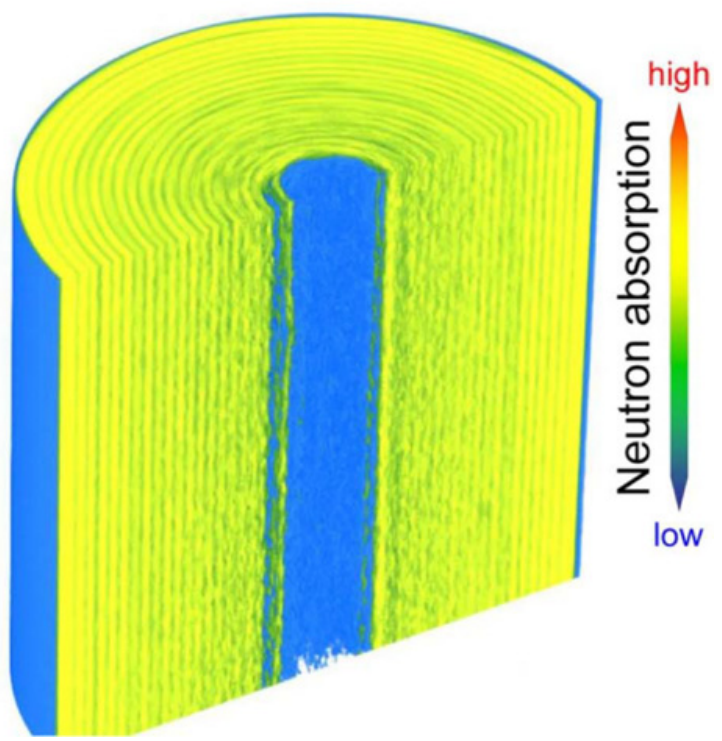

Figure 6. Neutron tomography of a commercial $18650 \mathrm{Li}$-ion battery discharged to 3.0 V. 3-D reconstruction from data acquired with a (left) "white" beam of cold neutrons at ANTARES, MLZ and (right) with a monochromatic beam $\lambda=1.5482 \AA$ at SPODI, MLZ. The left figure suggests an inhomogeneous Li distribution which can be unambiguously attributed to the artefacts from beam hardening [41].

angle scattering and grazing incidence scattering for localizing mesoscopic structures and those of thin film applications, and most important time and spatially resolved wide angle diffraction for following the reaction kinetics.

Tomography delivers a 3-D spatial distribution of the attenuation coefficients, which again are attributed to the different elemental compositions. In-operando studies allow the comparison of the different charge states and - because Li contributes considerably to the neutron attenuation - make a 3D mapping of the Li distribution possible. Figure 6 gives an example of the significance but also the limitations of such 3-D reconstructions. Using 600 single projections each with an exposure time of $60 \mathrm{~s}$ results in pictures with about 50 micron spatial (voxel) resolution. Steel can, gasket, safety vent and the circuits inside the Li battery as well as cathode/anode layers rolled around the centre pin are observed. The picture taken by the polychromatic beam of ANTARES seems to reveal a radial absorption gradient, which can be attributed to Li distribution. However, this can be attributed to beam hardening due to the high absorption coefficient of ${ }^{6} \mathrm{Li}$ and the same battery exposed to a monochromatic beam shows a rather homogeneous distribution of the Li. The optimized method can now/in the future be used to gain further insight into batteries under real operating conditions [38-41].

Wide angle neutron diffraction gives a much more detailed in-operando view of the battery organization on the scale of $\AA$ as well as kinetics inside the battery. The Rietveld analysis of the diffraction pattern allows a clear separation of signals corresponding to the anode, cathode, copper and aluminium current collectors and steel housing - see Fig. 7 and, consequently, separation of processes occurring there. A combination of above-mentioned advantages of neutron scattering along with the design of high-resolution diffractometer SPODI (whose peak resolution is independent on the diameter of studied samples) enabled structural studies of the entire battery at different external stimuli, e.g. stateof-charge, fatigue, temperature etc. Combined electrochemical and high-resolution powder diffraction 

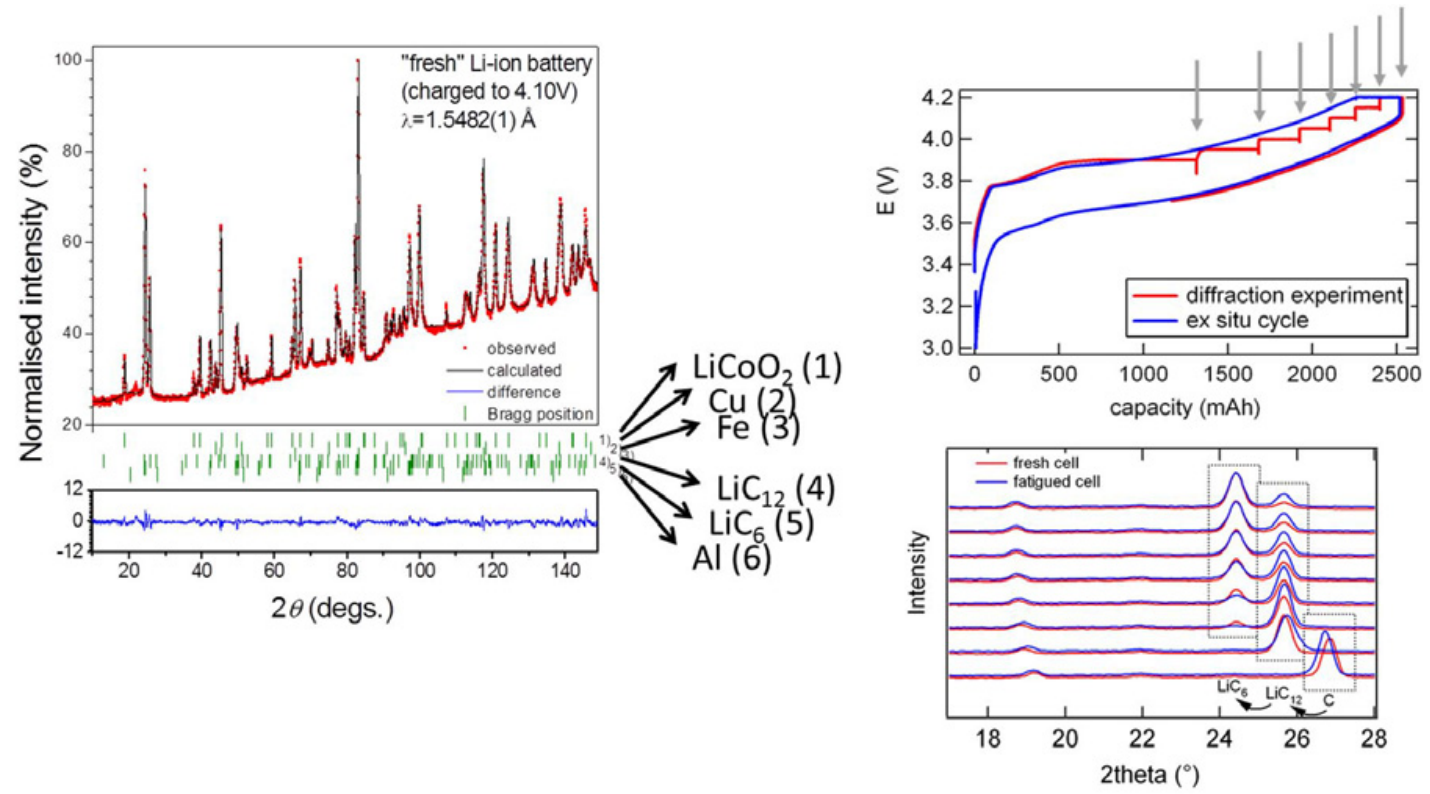

Figure 7. In-operando neutron diffraction of a commercial Li-18650 Li-ion cell. Left: Diffraction pattern with the corresponding Rietveld refinement identifying all the structures present in the neutron beam. These structures are then assigned to the anode $\left(\mathrm{LiC}_{12}+\mathrm{LiC}_{6}\right)$ and cathode $\left(\mathrm{LiCoO}_{2}\right)$. Right top: In-situ charging and discharging cycle. Right bottom: Change of the diffraction pattern during charging for a fresh and aged cell. By courtesy A. Senyshyn.

studies of $\mathrm{LiCoO}_{2} /$ graphite cell of 18650-type at different state of charges revealed a structural stability of $\mathrm{LiCoO}_{2}$ cathode in the entire capacity range [39] along with the quasi-continuous and modulated character of $\mathrm{LiC}_{12} \leftrightarrow \mathrm{C}$ phase transformation upon de $\backslash$ lithiation [42]. A complex character of phase diagram of Li-C binary system indirectly points on the non-equilibrium state in Li-ion batteries under real operating conditions thus making them challenging objects for theoretical description, prediction and simulations. Recently performed low-temperature studies of $\mathrm{LiCoO}_{2}$ /graphite cell of 18650-type [43] revealed an anomalous temperature behavior of lithiated graphites further attributed to their thermodynamic instability.

Systematic examinations of cells with introduced controlled fatigue (cycled continuously at constant temperatures) indicated a severe correlation of reduction in discharge capacity with the amount of lithium in cathode and anode [44]. Consequently a reduction of the amount of free movable lithium is believed to be the major reason for the degradation of cell performance upon cycling. Another effect significantly hindering the lithium diffusion is the cation mixing (an occupation of $\mathrm{Li}$ sites in the electrode material by a transition element, typically $\mathrm{Ni}$ ), whose quantification in-situ is technically challenging. Recent experiments on $\mathrm{LiNi}_{1 / 3} \mathrm{Mn}_{1 / 3} \mathrm{Co}_{1 / 3} \mathrm{O}_{2} /$ graphite cells at SPODI (MLZ) [45] indicated a reversible Li/Ni cation mixing independent on state-of-charge below $1600 \mathrm{mAh}$ and vanishing above $1800 \mathrm{mAh}\left(\sim 0.8 \mathrm{Q}_{\max }, \mathrm{Q}_{\max }=2200 \mathrm{mAh}\right)$.

Besides the studies of the entire Li-ion batteries, spatially-resolved neutron powder diffraction experiments can be performed at the engineering diffractometer Stress-Spec at MLZ, originally designed for the measurement of internal stresses, capable to define a scattering gauge volume of in the range of $\mathrm{mm}^{3}$ by the use of a radial collimator and a slit on the incoming neutron beam [41, 46]. The high neutron flux of Stress-Spec enables medium-resolution diffraction experiments on a limited angular range with the most prominent reflections of lithiated graphite collected in less than $5 \mathrm{~min}$, which can be used to follow the spatially resolved homogeneities of electrode materials and kinetics of the processes 
in the Li-ion cells "live". Recent combined studies (spatially - resolved neutron powder diffraction with $2 \times 2 \times 20 \mathrm{~mm}^{3}$ gauge volume, electrochemical measurements and X-ray computed tomography) performed on four different cell types under real cell operating conditions unambiguously revealed nonhomogeneity of lithium distribution in the graphite anode.

Such a study on commercial $\mathrm{LiNi}_{1 / 3} \mathrm{Mn}_{1 / 3} \mathrm{Co}_{1 / 3} \mathrm{O}_{2}$ /graphite cells at ambient and sub-ambient temperatures revealed precise information on the process of Li-plating. Today graphite is used as anode material in most Li-ion batteries. However, because the potential of lithium intercalation into graphite is within $100 \mathrm{mV}$ of the potential of $\mathrm{Li} / \mathrm{Li}+$, the development of metallic $\mathrm{Li}$ on the graphite anode, so-called Li-plating, can occur during fast charging. Whether Li plating occurs, depends not only on charging speed but also on factors like electrode balancing, the electrolyte used in the cell and on temperature. The consequences of Li plating can be severe safety problems, because metallic Li tends to be deposited in the form of dendrites which - in worst case - may pierce the separator and short-cut the cell. The study reveals in great detail the mechanism of plating, its dependence on charging speed and temperature and the ability of the battery to recover from plating, provided enough recovery time hours - is given to intercalate the metallic $\mathrm{Li}$ into the anode, transforming $\mathrm{LiC}_{12}$ and to $\mathrm{LiC}_{6}$. This shows metallic lithium in contact with the graphite anode is not stable and there is only a short time window for the detection of lithium plating by ex-situ methods, which makes in situ methods like neutron diffraction all the more important $[41,47]$.

A major degradation effect is the continuous decomposition of electrolyte - leading also to a growing solid electrolyte interface (SEI), a passivating layer on the anode active material (graphite), thus resulting in loss of conductivity and higher cell resistance. For the cathode phase transitions, structural disorder and metal dissolution are major aging effects. This has been verified ex-situ by PGAA. Like the above mentioned case, cathodes consisting of $\mathrm{LiNi}_{1 / 3} \mathrm{Mn}_{1 / 3} \mathrm{Co}_{1 / 3} \mathrm{O}_{2}$ were considered. The dissolution of $\mathrm{Mn}$, $\mathrm{Ni}$ and $\mathrm{Co}$ at higher voltages has been measured quantitatively. At high temperatures and (over)charge to higher voltages, increased dissolution, especially of Mn, was confirmed [48, 49].

The small-angle scattering method is commonly used to gain information about the nanostructure of the investigated materials (i.e., size, volume and shape of particles). It also measures as integrated quantity surface effects of particle the size of which is larger than the measuring range of SANS. In combination with the high penetration depth and contrast variation of neutrons in materials, small-angle neutron scattering (SANS) can be used as a powerful tool for in-situ and in-operando investigations of $\mathrm{Li}$-ion batteries. In a recent SANS experiment a pouch bag $\mathrm{Li}$ ion battery cell with $\mathrm{LiNi}_{1 / 3} \mathrm{Mn}_{1 / 3} \mathrm{Co}_{1 / 3} \mathrm{O}_{2}$ as cathode and graphite as anode material was investigated in operando during charging and discharging. The measurements were performed on the SANS-1 at MLZ. Among others micrometer graphite particles were present in the pouch cells. The integrated SANS intensity on a fixed geometry did catch the gradients in Li close to the surface of the graphite particles. And it could be nicely shown how it correlates with the measurement of the differential potential $\mathrm{dV} / \mathrm{dQ}(\mathrm{V}=$ charging voltage) versus charge $\mathrm{Q}$. All significant changes in the charge curve were mirrored by changes in the integrated SANS intensity. For instances the detailed Li-intercalation process of the anode from $\mathrm{C}_{\text {graphite }} \rightarrow \mathrm{LiC}_{12} \rightarrow$ $\mathrm{LiC}_{6}$ became visible. This means SANS allows the in-operando observation of the (de)charging process of pouch cells, thereby correlating the macroscopic variables (cycles, temperature, charging speed, material dependence ... ) to the nanoscale electrochemistry. Small and wide angle scattering thus allow developing models for understanding and optimization of batteries on the atomic level [50].

One route to further improve Li-ion batteries is the search for alternative material combinations for the anode and cathode. Serious efforts have been already paid to the development of high-voltage spinellike cathodes, whose 3D lithium diffusion pathway makes them suitable for high-power applications and high operating voltages enable to achieve nominally higher energy density. There $\mathrm{LiCrMnO}_{4} \mathrm{spinels}$ with a small degree of $\mathrm{Mn}$ substitution by $\mathrm{Cr}$ are promising high voltage cathode materials for Li ion batteries. Compared to $\mathrm{Mn}$ based $\mathrm{LiMnO}_{4}$, spinels with mixed $\mathrm{Cr} / \mathrm{Mn}$ compounds allow to increase the operating voltage from 4.1 to $5 \mathrm{~V}$ and therefore improve the specific energy of the cell. Despite the 
significant improvement in the cell voltage introduction of more than $10 \%$ of $\mathrm{Cr}$ leads to fast capacity losses during cycling. Different mechanisms of degradation are presently considered. Structural features of the $\mathrm{Li}$ extraction from a $\mathrm{LiCrMnO}_{4}$ cathode were investigated by synchrotron and neutron diffraction. The observed diffraction pattern reveals that both Li-extraction during cell charging and the following $\mathrm{Li}$ insertion upon discharge are a one solution process. However a kink in the composition dependence of the lattice parameter suggests a change in the charge compensation mechanism above $4.9 \mathrm{~V}$. A formation of toxic $\mathrm{Cr}^{6+}$ is proposed. The much slower Li-reintercalation back into $\mathrm{LiCrMnO}_{4}$ above $4.9 \mathrm{~V}$ can be attributed to the high observed capacity loss. Moreover a significant loss of $\mathrm{Cr}$ from the crystalline phase has been observed. The highly oxidized $\mathrm{Cr}^{6+}$ may be removed from the spinel structure and either segregate on grain boundaries as a SEI layer or partially dissolve in the electrolyte [51].

Nanostructured electrode materials for Li-ion batteries offer enhanced storage kinetics through shorter Li-ion and electron diffusion paths. Additionally the high surface to volume ratio leads to a significant increase of lithium storage capacity. Grazing incidence X-ray and neutron small angle scattering on self-organized anodic $\mathrm{TiO}_{2}$ show an average porosity of $46 \%$, distinct signature of prominent lateral correlation of the nanotubes and their preferential crystallographic orientation. The latter one is expected to be advantageous for lithation/delithiation. Additional coating of the nanotubes with $\mathrm{Si}$ results in an additional $17 \%$ increase in the specific charge capacity [52].

Sodium metal halide batteries, first invented in the 80's are used today both for stationary and mobile applications. Advantages of such molten salt Na/ $\mathrm{MCl}_{2}(\mathrm{M}=\mathrm{Ni}, \mathrm{Fe})$ batteries are a high specific energy density of $\sim 140 \mathrm{Wh} / \mathrm{kg}$ - four times higher than lead acid batteries - in combination with a high cyclability (more than 3000 cycles at $80 \%$ depth of discharge (DoD)) without need of maintenance. These features make sodium metal halide batteries well suited for stationary telecom applications, for example in areas with poor grid connection and frequent power outages, where also the fact that the batteries can be operated under elevated or extreme temperature conditions proves to be useful. Additionally, sodium metal halide cells can be charged and discharged rapidly and are safe in operation, which makes them especially suitable for mobile applications such as cars, vans and busses. Current applications also comprise use as energy backup system for railed vehicles. Finally, sodium metal halide batteries have the benefit of being $100 \%$ recyclable.

Because of the large cell cross section $(35 \times 35 \mathrm{~mm})$ and elevated cell operation temperature $\left(270-350^{\circ} \mathrm{C}\right)$ sodium metal halide cells can usually be studied only by ex-situ analytical methods. That means the cell has to be cooled to room temperature, cut open in a glove box, disassembled and then prepared for analysis. During these processes, the chemical composition or distribution of phases within the cell may be altered. Thus it is very interesting to gain information on the cell in the actual operating state and during the whole process of charging and discharging.

Neutron tomography and diffraction are by far best suited for these spatially resolved in-operando characterizations. Since the reaction travels through the cathode of the cell during charge, looking at one fixed position in the cell only gives an incomplete picture of the processes in the cell, and collecting data at several positions with different distance to the ceramic separator is necessary to see how the reaction front propagates through the cell with time during charge. Thus the processes in the cell can be simultaneously mapped in space and time.

Neutron diffraction data at different positions in the cathode of a sodium metal halide cell with mixed $\mathrm{Fe} / \mathrm{Ni}$ chemistry during operation and 3-D neutron tomography provided the first in situ and simultaneously spatially resolved data on the processes occurring in such a cell during charge and discharge. Thus, it was possible to map how the different reactions proceed with time. During charge as well as discharge, reactions start close to the $\beta$ "-alumina and proceed towards the cell interior. Separate reaction zones move through the cathode for $\mathrm{Fe}$ and $\mathrm{Ni}$ oxidation as well as for $\mathrm{Na}_{6} \mathrm{FeCl}_{8}$ and $\mathrm{NaCl}$ usage as $\mathrm{Cl}^{-}$and $\mathrm{Na}^{+}$source in the latter case. There is one reaction zone per redox reaction, during charge as well as during discharge. Reaction zones can encompass $1.7 \mathrm{~mm}$ or more and their broadness may vary with time, depth and the respective reaction. Further information about processes like the formation 


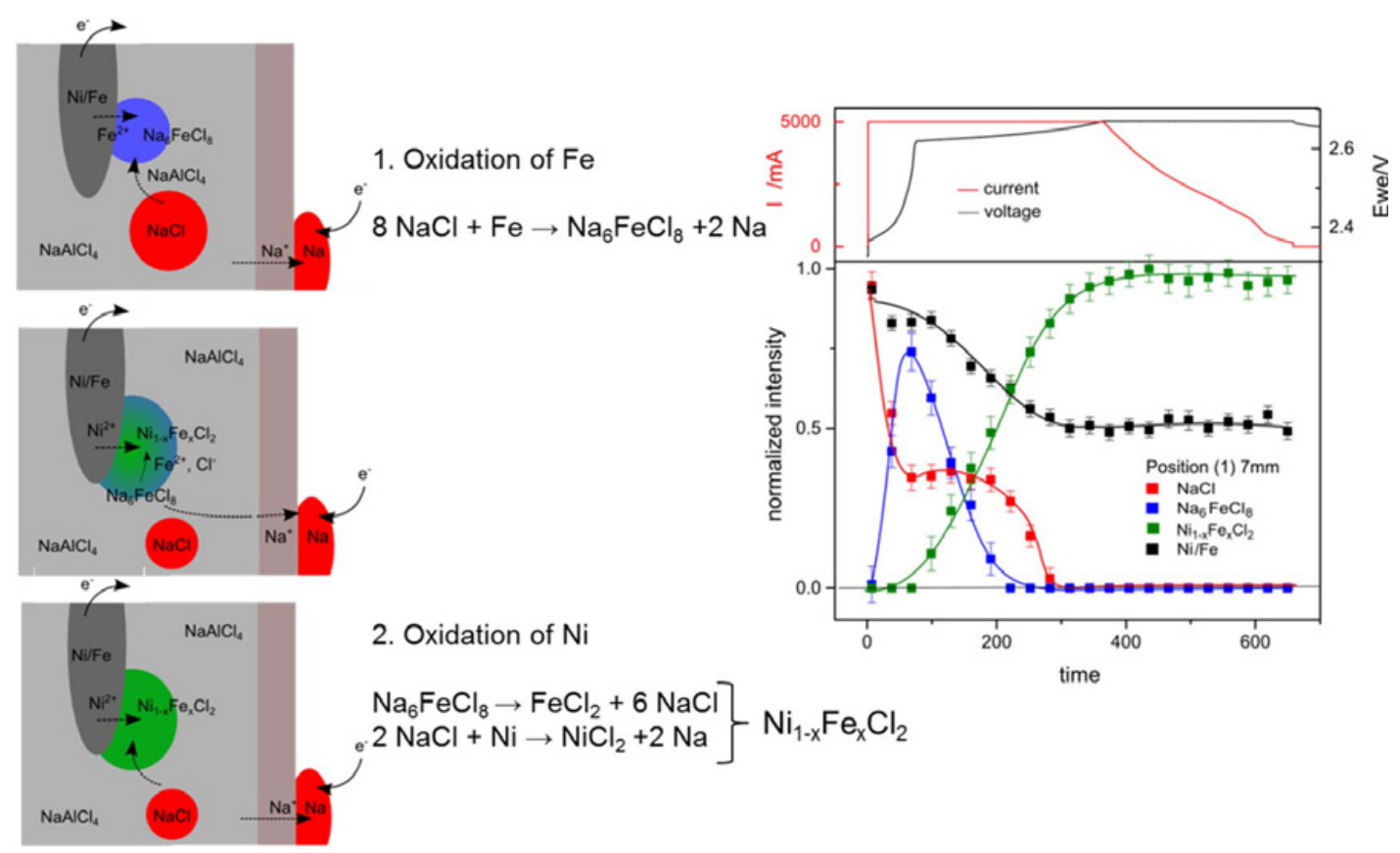

Figure 8. Charging of a Sodium Metal Halide Battery $\mathrm{Na} / \mathrm{MCl}_{2}(\mathrm{M}=\mathrm{Ni}, \mathrm{Fe})$. Right: Applied current and voltage during charging of the battery and corresponding fraction of chemical compounds in the course of charging as detected by diffraction at a position $7 \mathrm{~mm}$ towards the inner part of the battery. Middle and left: sequence of the oxidation of the cathode by courtesy V. Zinth.

of $\mathrm{Ni}_{1-x} \mathrm{FexCl}_{2}$ and a possible slight overcharge close to the $\beta$ "-alumina has been identified. Figure 8 sketches a simplified mechanism of processes during charging. Thanks to the selectivity of neutron diffraction data it is possible to study every single reaction that takes place inside the cell at the same time and the relationship between them, in time and space. The study is a basis for future improvements in the composition of the cathode through the optimization of the quantity of main components $(\mathrm{NaCl}$, $\mathrm{Fe}, \mathrm{Ni}$ ) in order to increase the energy density of a sodium metal halide cell $[53,54]$.

\section{Organic solar cells}

As an alternative renewable energy technology, polymer solar cells (PSCs) experienced compelling progress on the basis of device efficiency and lifetime in the past decades. Although the power conversion efficiency (PCE) of traditional crystalline silicon has reached $25 \%$ with a typical lifetime of about 20 years and PSCs have achieved only PCE values of 12\% with reported 7 year operating lifetimes, PSCs have promising advantages as compared to the traditional silicon solar cells such as mechanical flexibility and the use of lightweight materials. Moreover, PSCs promise feasible cheap device fabrication costs and a rapid energy payback time. However, to unlock the great potential of PSCs and to achieve a breakthrough in applications, further improvements of the device performance of PSCs are needed. Many approaches, such as the synthesis of new low-bandgap polymers, the introduction of solvent additives, the optimization of device geometry, post production treatments with thermal or vapor annealing, and interface engineering, have been examined. To date, the highest published PCE of PSCs in a single junction device has reached $10 \%$, above which commercialization is feasible. 
For further improvements buried interfaces have to be characterized. To detect inner structures, diffuse scattering needs to be applied, and the grazing incidence geometry has proven to be very well suited for this task. Using neutrons instead of X-rays has the particular advantage that contrast conditions are improved in systems relevant for PSCs.

Recent publications applying grazing incidence small angle neutron scattering (REFSANS, MLZ) address questions like phase separation and molecular intermixing in polymer-fullerene bulk heterojunction thin films [55], infiltration of polymer hole-conductor into mesoporous Titania structures for solid-state dye-sensitized solar cells [56], or the effect of an environmentally friendly alcohol treatment on bulk heterojunction polymer solar cells [57].

\section{Tailoring internal stresses, a key issue for sustainable mobility}

Residual stresses are stresses that are always present in a material or component in some extent due to the manufacturing process. They are equilibrated within the component and so cannot, on their own, cause plastic collapse; rather, they superimpose on the in-service stresses and might lead to premature and unexpected failure of components. Several techniques have been developed to determine stresses within engineering components. Most of them are destructive or limited to surface layers. Only neutron and to a lesser extend synchrotron-produced hard x-ray diffraction are able to provide a true threedimensional determination of residual stresses without damaging the specimen. This is due to the relative transparency of many materials to neutrons, particularly those of engineering components see Fig. 1 [58].

The measuring principle is straight forward. Changes in lattice parameters $d+\Delta d$ caused by the internal stresses are measured relative to the thermally equilibrated stress free specimen with lattice spacing d. Form this the strain $\Delta \mathrm{d} / \mathrm{d}$ is calculated from which stress can be determined using Hooke's law taking so called diffraction elastic constants into account. In general the change in lattice spacing is measured as $\Delta \mathrm{d}_{\mathrm{hkl}}$, i.e. identifying the different structures in the sample. Because of the tensor characteristic of stress, measurements are required in six independent orientations. However, often principal directions can be inferred from the symmetry of the specimen so that it is sufficient to align those axes of the sample along the scattering vector of the diffraction set-up to decrease measurement time. Integrated over the specimen residual stresses sum up to zero, i.e. part of the questions to tackle is always their local distribution. The sampling volume is given by the crossing of the well collimated incoming and scattered beam and the sample is usually scanned through that point. For most applications the sampling volume is large enough to average over many grains and structures and consequently the stress at that point can be determined. Micro-stresses as they are attributed to different grains and phases or the interface between grains are of similar importance for optimizing materials behavior. They can be addressed by detailed Bragg-peak analysis or more elaborated methods like Larmor diffraction [59-61].

Given the importance of residual stresses in designing work pieces and the unique capability of neutrons to determine those non-destructive, in depth, in-operando, 3-dimensional and spatially resolved all of the before mentioned neutron sources have dedicated diffractometers and specialized sample environment to serve directly industry and industry related research. At MLZ this is the materials science diffractometer Stress-Spec [62]. Because residual stresses often depend on texture properties of the sample Stress-Spec is also equipped with goniometers and detectors for optimized texture analysis which ideally could be performed on the identical sample. In favorable cases the sampling volume may be reduced to $1 \mathrm{~mm}^{3}$. At surfaces the transversal resolution extends to some $100 \mu \mathrm{m}$. Precision of $\Delta \mathrm{d} / \mathrm{d}$ in the order of $10^{-4}$ are routine, using Larmor diffraction unprecedented $10^{-6}$ are feasible on technical relevant specimens [61].

The increasing demand for light weight and efficiency of modern combustion engines requires sophisticated light weight alloys with improved high-temperature strength, creep resistance and long-term stability under operating conditions. Such light weight AlSi based alloys are used for the casting of light 


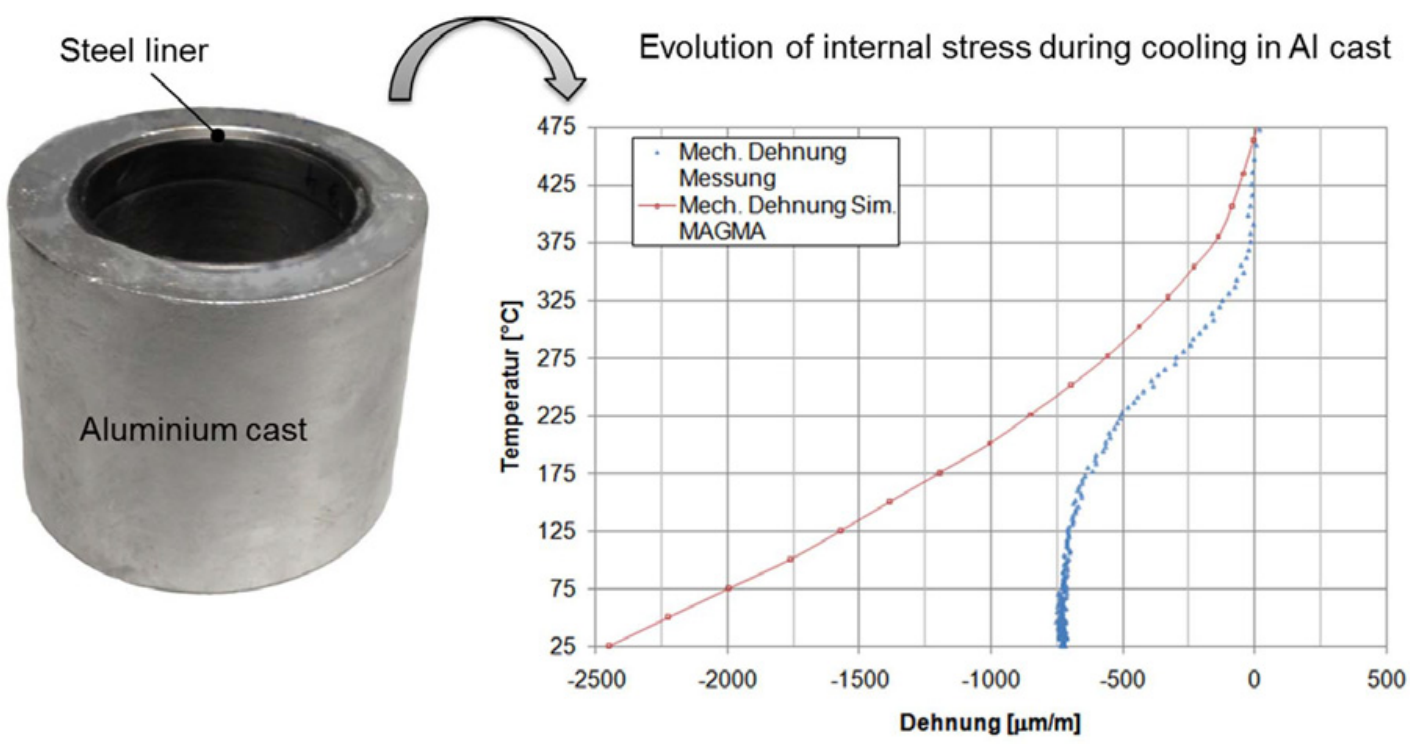

Figure 9. Evolution of residual stress during cooling in Al model cast, simulating a light weight motor block cast. Left: Model cast of AlSi alloy with a steel liner inside. Right: Build-up of tangential strain in the steel liner during cooling by courtesy M. Hofmann.

weight engine blocks with in-cast liners made of steel to guarantee sufficient wear resistance for the moving pistons. The heterogeneous microstructure of AlSi combines the thermal properties of segregated stiff Si particles with ductile $\alpha$-Al into a composite with sophisticated thermomechanical strength. Due to the different thermal expansion of the casting material and the liner steel residual stresses develop during solidification. Simulations of the residual stresses often performed by phase field analysis and by finite element calculations have gained increasing importance. Specialized casting simulation programs are available, the validity of which, however, has to be verified by suitable experiments.

Reproducing the basic elements of a modern motor block a composite specimen consisting of a steel insert and an AlSi cast surrounding has been casted in sand molds and alternatively in a steel mold in-situ at the sample position of StressSpec. The steel mold can be repeatedly used for casting. Different AlSi alloys as well as different liner steels have been tested. The temperature and time dependent change of the lattice spacing and thus the strain evolution was investigated by in-situ experiments directly after casting at the diffractometers sample position and during the cooling of the part.

Figure 9 gives an impression of the outcome. Shown is the build-up of compressive tangential strain in the steel liner. The data are corrected by "normal" thermal expansion effects. Coming from the melt temperature of the AlSi alloy there is still enough viscous flow in the already solidified cast to compensate for the different thermal shrinking of cast and liner down to about $375^{\circ} \mathrm{C}$. Yet no strain builds up. From $375^{\circ} \mathrm{C}$ downwards elastic compression of the liner sets in. Around $225^{\circ} \mathrm{C}$ the slope of this increasing strain starts to diminish continuously down to almost zero at room temperature. This inflection point at $225^{\circ} \mathrm{C}$ is the signature of the onset of plastic flow in the AlSi. The deformation in the liner steel remains purely elastic. Many more strain data have been measured, studying the influence of different cooling speed for sand and steel molds, different combinations of cast and liner material, in all main directions (hoop, tangential, radial) in the liner and in the mold. In particular theses in-situ non-destructive measurements have been compared to conventional destructive stain measurements at room temperature, always confirming the neutron results. The industrial relevance of this detailed study is best visualized by comparison with the results from a numerical casting simulation as routinely used 
in industry. The left part of Fig. 9 shows such a simulation of the build-up of the internal strain. The need for correction of the simulation is evident [63-65].

Materials with high thermal conductivity (TC) in combination with a low coefficient of thermal expansion (CTE) are required for high power electronic devices in order to dissipate heat from the chip to a heat sink. Particle reinforced composites such as AlSi/SiC exhibit a reduced CTE and moderate TC when compared to pure metals and are considered as candidates for the thermal management of high power electronics. Mixing diamond particles with an excellent TC and low CTE into such composites could compensate for the too low TC of the AlSi matrix. In-situ neutron strain and stress analysis along thermal cycles between RT and $350{ }^{\circ} \mathrm{C}$ for such heat sinks simulated the requirements for heat management during fabrication and operation. It could be shown, that an interconnected Si-CarbonDiamond network forms in the AlSi7 matrix. This network produces isotropic matrix compression during heating, by which voids and delamination is stopped, so improving conductivity. Tensile stresses induce debonding during cooling by matrix shrinking, where lower conductivity is required. Thermal fatigue damage propagation is reduced by creating the interpenetrated composite network. In summary these interpenetrating networks are superior in heat management when compared to particles mixed into a pure Al matrix [66].

Here just two examples are cited. Non-destructive in depth and spatially resolved stress determination belongs to the most urgent requests of industry for the usage of neutrons. Further catchwords for such application are weld testing, surface treatment, hardening, high temperature materials for turbines, fatigue, etc.

\section{Neutrons for medicine}

Neutrons are indispensable for modern nuclear medicine. By neutron capture radioisotopes are produced which serve for both diagnostics and curative purposes. Whereas the production of the radioisotopes is done by the neutron source operator, its transformation to a radio pharmaceutic is the matter of industry. To minimize the transportation of the irradiated and highly radioactive targets this radiopharmaceutical industry is often located near to the neutron source as it is for instance the case at the HFR at Petten, Netherlands. Similarly, pharmaceutical industry operates laboratories on the FRM II site.

For some years, ${ }^{177} \mathrm{Lu}$ (Lutetium) has been used in the treatment of neuroendocrine tumors and/or metastases, such as those that occur in the pancreas. ${ }^{177} \mathrm{Lu}$ is in this case coupled to a protein molecule, a so-called "ferry", and thus moves directly into the tumor. ${ }^{177} \mathrm{Lu}$ is a beta emitter with the very low range of about two millimeters, which means that healthy tissue remains virtually undamaged.

Figure 10 sketches the alternative routes to produce ${ }^{177} \mathrm{Lu}$. Conventionally it is produced by neutron capture at the stable isotope ${ }^{176} \mathrm{Lu}$. Unavoidably this is accompanied by the parallel creation of a metastable state of ${ }^{177} \mathrm{Lu}$ which decays over the long time of 160 days, an activity not wanted for the cancer treatment. The specific activity after chemical extraction of the ${ }^{177} \mathrm{Lu}$ is further diluted by the chemical equivalent and stable ${ }^{176} \mathrm{Lu}$ isotope. At the FRM II, ${ }^{177} \mathrm{Lu}$ is produced from the irradiation of enriched ${ }^{176} \mathrm{Yb}$ (Ytterbium) through a very short-lived nuclide ${ }^{177} \mathrm{Yb}$, which quickly decays to ${ }^{177} \mathrm{Lu}$. This process guarantees pure ${ }^{177} \mathrm{Lu}$ (free of stable ${ }^{176} \mathrm{Lu}$ ) which can then be used without a carrier. This means largely increased specific activity, no long-living radioactive background irradiation, less radioactive waste for clinics, and the radioactivity can be used for a longer time since, even after 7-10 days, it still contains a sufficient amount of therapeutically active ${ }^{177} \mathrm{Lu}$. In summary the dose to which the patient has to be exposed is reduced by about a factor of two compared to the conventional treatment.

This technically very complex method was developed by Radiochemistry of TUM and is utilized commercially today by the ITM Isotope Technologies AG Munich on the site of the FRM II [67].

One of the most commonly used radioisotope in nuclear medicine is ${ }^{99 \mathrm{~m}} \mathrm{Tc}$ (Technetium), the daughter isotope of ${ }^{99} \mathrm{Mo}$ (Molybdenum). ${ }^{99 \mathrm{~m}} \mathrm{Tc}$ is used in up to $80 \%$ of in-vivo diagnostic applications. 


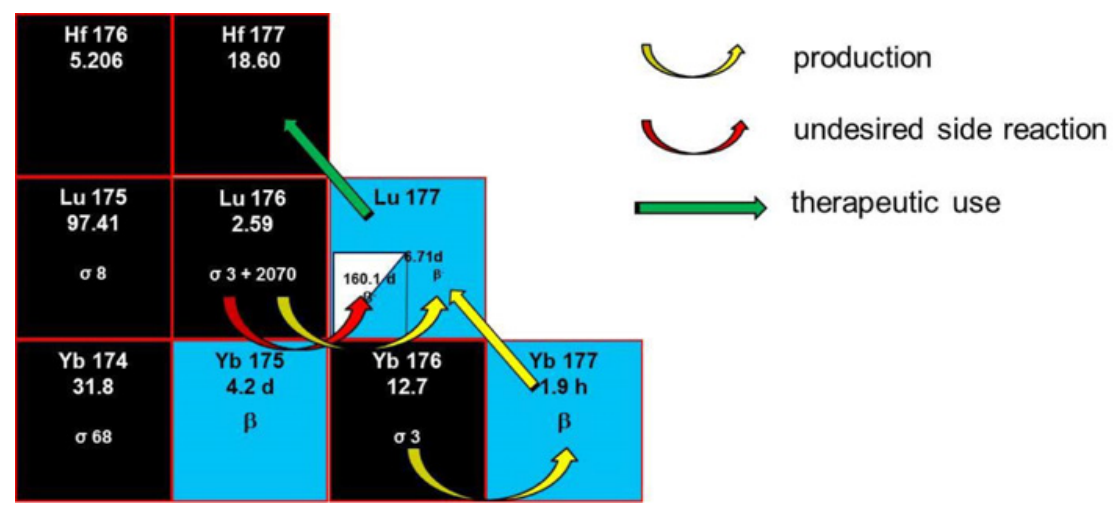

Figure 10. Excerpt of the nuclei table showing different path for the production of ${ }^{177} \mathrm{Lu}$. Conventionally the stable isotope ${ }^{176} \mathrm{Lu}$ is exposed to thermal neutrons with the unavoidable parallel production of the metastable ${ }^{177} \mathrm{Lu}$ with a live time of $160 \mathrm{~d}$. Further ${ }^{177} \mathrm{Lu}$ cannot be extracted carrier free. Irradiating enriched ${ }^{176} \mathrm{Yb}$ leads over the short living ${ }^{177} \mathrm{Yb}$ directly to ${ }^{177} \mathrm{Lu}$, which can be extracted carrier free with high specific activity.

This corresponds to more than 30 million tests worldwide each year - in Europe alone about 9 million tests per year. It is mainly used for the investigation of thyroid function, but also for the diagnosis of diseases of other organs such as the lungs, heart, liver, gall bladder and the skeleton. Depending on the application, the ${ }^{99 \mathrm{~m}} \mathrm{Tc}$ can be attached to a suitable "smart" carrier molecule, which later recognizes, for example, tumor cells in a patient and docks with them. The patient is injected with ${ }^{99 \mathrm{~m}} \mathrm{Tc}$ with or without a pharmaceutical label. When decaying to ${ }^{99} \mathrm{Tc},{ }^{99 \mathrm{~m}} \mathrm{Tc}$ emits $\gamma$-radiation, which is then measured depending on the location. The short lifetime of 6 hours of the diagnostic isotope ${ }^{99 \mathrm{~m}} \mathrm{Tc}$ and the low energy of the $\gamma$-rays minimize the exposure of the patient to radiation. Figure 11 shows an example of molecular imaging of an abnormal bone metabolism in a human ankle joint.

The most efficient and widely used method for the production of ${ }^{99} \mathrm{Mo} /{ }^{99 \mathrm{~m}} \mathrm{Tc}$ is nuclear fission. The manufacture process of ${ }^{99 \mathrm{~m}} \mathrm{Tc}$ involves the fission of ${ }^{235} \mathrm{U}$ to the fission product ${ }^{99} \mathrm{Mo}$, which decays to ${ }^{99 \mathrm{~m}} \mathrm{Tc}$ with a half-life of 66 hours. ${ }^{99 \mathrm{~m}} \mathrm{Tc}$ itself decays with a half-life of 6 hours to the quasi stable ${ }^{99} \mathrm{Tc}$ while emitting low energy gamma radiation.

$$
{ }^{235} \mathrm{U} \stackrel{\mathrm{n}, \mathrm{f}, \sigma=568 \mathrm{barn}, 6 \% \text { yield }}{\longrightarrow}{ }^{99} \mathrm{Mo} \underset{{ }^{66 \mathrm{~h}}}{\longrightarrow}{ }^{99 \mathrm{~m}} \mathrm{Tc} \underset{6 \mathrm{~h} .0 .14 \mathrm{MeV}}{\longrightarrow}{ }^{99} \mathrm{Tc}
$$

For irradiation enriched $\mathrm{U}(20 \%)$ targets with a max. ${ }^{235} \mathrm{U}$ mass of $4 \mathrm{~g}$ are irradiated for typically 6 days in a high thermal neutron flux. Because the fission reaction is accompanied by considerable heat release special care has to be taken to evaporate the heat during irradiation. Since both ${ }^{99}$ Mo with 66 hours and ${ }^{99 \mathrm{~m}} \mathrm{Tc}$ with 6 hours have short half-lives, it is immediately clear that ${ }^{99 \mathrm{~m}} \mathrm{Tc}$ cannot be stored. Therefore, the various steps in the production chain - chemically dissolution of the target, extraction of ${ }^{99} \mathrm{Mo}$, splitting the ${ }^{99} \mathrm{Mo}$ activity in small portions, packaging in generators and distribution of those to hospitals - must proceed swiftly and be well-coordinated in order to supply hospitals with the necessary amount of ${ }^{99 \mathrm{~m}} \mathrm{Tc}$ at the right time. In the generators ${ }^{99} \mathrm{Mo}$ continues to decay to ${ }^{99 \mathrm{~m}} \mathrm{Tc}$, which is then eluted or "milked" on-site at the hospital.

Due to the transient nature of the initial isotope ${ }^{99} \mathrm{Mo}$ and the high demand for ${ }^{99 \mathrm{~m}} \mathrm{Tc}$, Europe requires its own medium and long term secured supply chain for ${ }^{99} \mathrm{Mo} /{ }^{99 \mathrm{~m}} \mathrm{Tc}$. Today European supply with ${ }^{99} \mathrm{Mo} /{ }^{99 \mathrm{~m}} \mathrm{Tc}$ relies on four MTR reactors, BR2 in Belgium, HFR in Netherlands, MARIA in Poland and LVR-15 in Czech Republic. All these reactors are supposed to phase out in the 2020th due to age. With the completion of the ${ }^{99} \mathrm{Mo}$ irradiation facility currently under construction at the FRM II in Germany 


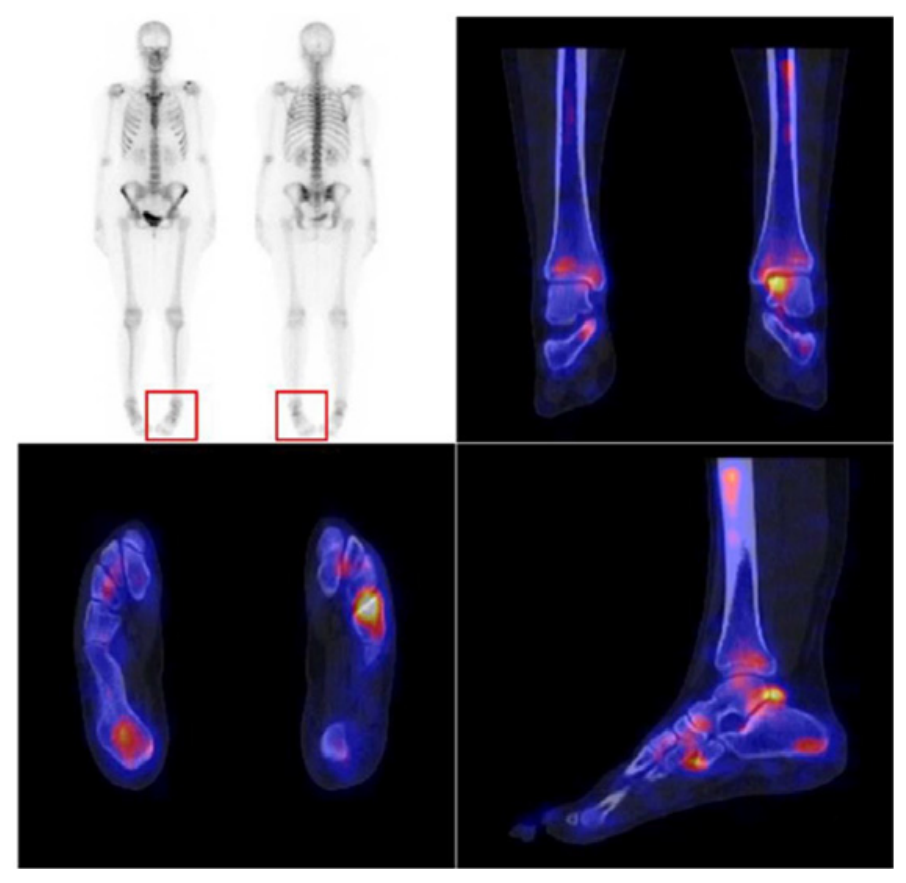

Figure 11. Bone scintigraphy of an Articulatio talocruralis (ankle joint) by means of ${ }^{99 m}$ Tc. The images show a SPECT-CT recording of a left ankle. Hereby a conventional X-ray tomography is superimposed by a scintigraphy using ${ }^{99 \mathrm{~m}} \mathrm{Tc}$ as a $\gamma$-emitting radioisotope. The bright areas show an abnormally increased bone metabolism indicating an inflammation [68].

and the commissioning of the RJH, currently under construction in Cadarache, France the European supply of ${ }^{99} \mathrm{Mo} /{ }^{99 \mathrm{~m}} \mathrm{Tc}$ will be secured also for future [69-71].

Beams of fast neutrons have a higher relative biological effectiveness (RBE) in destroying tumour cells than high energetic photon and proton beams (so-called low-LET radiation). During the interaction with the DNA, fast neutrons lead with considerable higher probability to irreparable damage of the double helix. As a consequence, the cell is deactivated. The main advantage of fast neutrons is their higher effectiveness in the treatment of tumour regions with poor blood supply, because hypoxic cells need about $300 \%$ more low-LET radiation dose than those with normal oxygen content; in contrast, the difference in effectiveness for the beam at FRM II is only 30\%. Similar arguments hold true for slowly growing tumours which contain many cells in the rest phase of the cell cycle during which they are less sensitive to low-LET radiation. The good repair capacity of highly differentiated tumour cells is another obstacle in the radiation treatment of tumours, and also here, fast neutrons offer advantages. Due to the low oxygen effect of neutrons, also fewer fractions are needed. Side effects are as low as in conventional radio therapy. In summary, the RBE of fission neutrons is 3-6 in comparison of 1 for irradiation with photon or proton radiation. Fast neutrons do not penetrate deep into the human body due to its high water content. In the language of the nuclear engineer, human tissue is an excellent moderator. In fact the diffusion length of fast neutrons into human tissue is about $5 \mathrm{~cm}$. Therefore, only patients suffering from superficial tumors, e.g., in the head and neck area, breast cancer and melanoma metastases are deemed suitable for irradiation using reactor neutrons. The small penetration depth is offset by the very high efficiency of neutron beams: It is possible to locally suppress the growth of tumours that are resistant to other forms of radiation and which can no more be treated using other therapies (mostly palliative cases). 


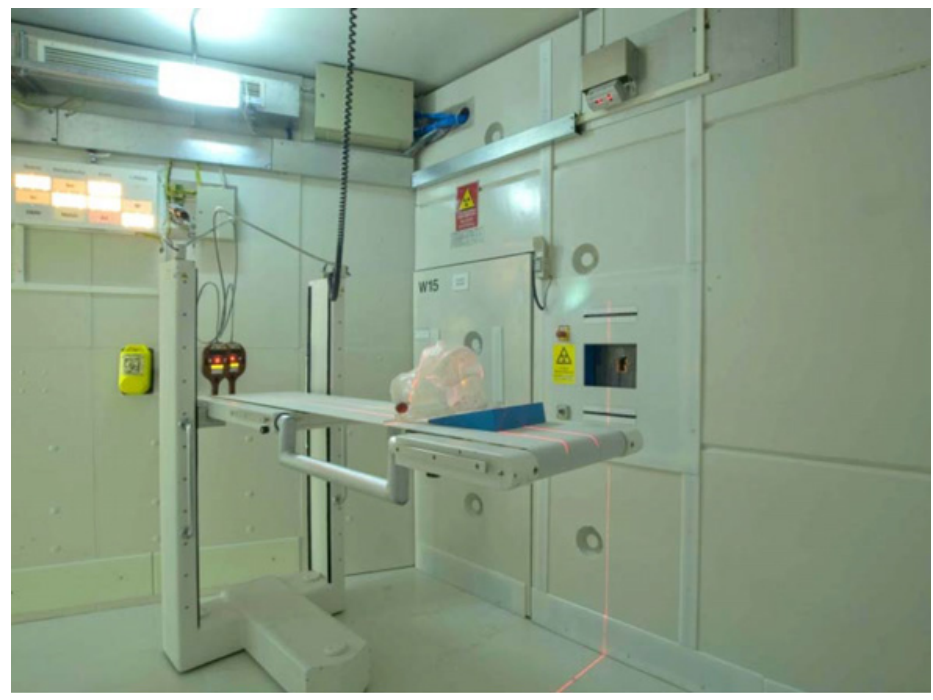

Figure 12. View into the MEDAPP irradiation chamber. The beam of filtered $2 \mathrm{MeV}$ fission neutrons enters into the treatment room through the dark rectangular in the center of the picture. By means of laser tracking a leave collimator focuses the fast beam on the patient. Typical irradiation times are $2 \mathrm{~min}$.

Due to their energy spectrum, fission neutrons (energy 0.1 to $10 \mathrm{MeV}$ ) exhibit the highest RBE of all neutron beams used to treat cancer. The FRM II has a special and worldwide unique system which allows the provision of an external beam of $2 \mathrm{MeV}$ fission neutrons. The system, a so-called neutron converter, consists of two uranium plates located approximately $1 \mathrm{~m}$ from the fuel element in the heavy water moderator at the tip of a beam tube. The thermal neutrons in the moderator induce fission processes in the $\mathrm{U}$ plates from where fast reactor neutrons and gamma radiation can escape without moderation. In close collaboration with the Department of Radiation Therapy and Oncology at the TUM, the MEDAPP cancer treatment facility has been set up along that beam and allows clinical applications. Figure 12 opens a view on the MEDAPP irradiation chamber, located some $5 \mathrm{~m}$ away from the center of FRM II's core [72].

\section{New area detection for neutron application}

Certainly basic research drives advances in neutron instrumentation. However the cost effective transformation of new ideas into an innovative technology is best done by industry. Developing large area detectors for the need of the up-coming European Spallation Source (ESS) at Lund might become such an example. Due to the present shortage of ${ }^{3} \mathrm{He}$ and the associated tremendous increase of its price, the supply of large neutron detection systems with ${ }^{3} \mathrm{He}$ becomes unaffordable. Alternative neutron detection concepts, therefore, have been invented based on solid ${ }^{10} \mathrm{~B}$ converters. These concepts require development in thin film deposition technique regarding high adhesion, thickness uniformity and chemical purity of the converter coating on large area substrates. A recent study on REFSANS reports on the sputter deposition of highly uniform large-area ${ }^{10} \mathrm{~B}_{4} \mathrm{C}$ coatings of up to $2 \mu \mathrm{m}$ thickness with a thickness deviation below $4 \%$ using the Helmholtz-Zentrum Geesthacht large area sputtering system. The specular geometry of REFSANS has been used to study the conversion efficiency under different inclination angle of the incoming neutron with respect to detection surface. The idea behind is to increase the footprint of the neutron by a given thickness of the ${ }^{10} \mathrm{~B}_{4} \mathrm{C}$ layer. The test measurements demonstrate an average relative quantum efficiency ranging from $65 \%$ to $90 \%$ for cold neutrons as compared to a black ${ }^{3} \mathrm{He}$-monitor. 
Thus, the advanced ${ }^{10} \mathrm{~B}_{4} \mathrm{C}$ coatings are promising candidates for replacing ${ }^{3} \mathrm{He}$ in large scale neutron detectors. Transferring the presented preparation process to a large-scale industrial system would deliver highly uniform ${ }^{10} \mathrm{~B}_{4} \mathrm{C}$ neutron converter coatings for alternative, ${ }^{3} \mathrm{He}$-free large-area neutron detection systems. Similar progress has been reported by a collaboration of several groups with the ESS [73, 74].

\section{Access to neutrons for industry}

Large scale research facilities like neutron sources are owned by the public sector. The neutron sources relevant for this article have all user access programs and the primary route to get access for beam time is to apply for on the base of a scientific proposal, i.e. to prove the excellence of the proposal in competition with others. Once the proposal has overcome this barrier the beam time is allocated in general free of charge. Under the important condition, that the results are published under peer reviewing and thereby accessible to the public (who has payed for). An inherent drawback of this free access on the base of scientific attractiveness is the long time needed between submitting a proposal and measurement achieved - often up to year. To mitigate this most of the facilities offer a so-called rapid access for timely characterizations. In case the industrial user needs urgently access and wants to be the only owner of the result, all these facilities offer the possibility to buy beam time. The same holds true for those applications where neutrons are part of production like Si doping, radioisotopes for nuclear industry or for routine characterizations like elemental analysis by NAA or PGAA.

\section{Concluding remarks}

Examples how neutrons serve industrial needs have been given, including service for the health sector. Well known applications with considerable impact on the engineering of industrial products like small angle scattering for polymer characterization or for the characterization of the mesoscale in functional (hard) materials, atomistic characterization of magnetic materials, high temperature alloys for turbines etc. have not been mentioned but are of equal relevance as the examples shown here.

Neutrons are a unique tool for materials science, from hard to soft matter. This uniqueness relies on the privileged penetration of neutrons in any kind of matter, their particular contrast for different elements/isotopes, their capability to characterize in situ, in operando and in real time. Often enough neutron research explains the functionality of materials and work pieces by their atomistic foundation and opens the way for optimization of the functionality. Today neutron sources offer a wide spread range of applications for industrial need, covering the whole Technological Readiness Levels. They do not only characterize but are also produce smart materials.

\section{References}

NECTAR

[1] T. Bücherl, Ch. Lierse von Gostomski

Radiography and Tomography using fission neutrons at FRM II

16th World Conference on NDT-2004 - Montreal (Canada), http://www.ndt.net/article/ wcndt-2004/pdf/radiography/145_ bucherl.pdf

[2] T. Bücherl, Ch. Lierse v. Gostomski, H. Breitkreutz, M. Jungwirth, F.M. Wagner NECTAR - A fission neutron radiography and tomography facility

Nucl. Inst. \& Meth. in Physics Research A 651 (2011) 86

NEA data base

[3] NEA nuclear data base http://www. oecd-nea.org/janisweb/index.html 
Electronics for space application

[4] B. Gudehus, J. Zabel, K. Krüger, K. Simon

Neutroneninduzierte Störungen in MOS-Elektronik

VDI Expertenforum 2010, Garching 13. April 2010

[5] D. Doering, M. Deveaux, M. Domachowski, C. Dritsa, I. Froehlich, M. Koziel, C. Muentz, S. Ottersbach, F.M. Wagner, J. Stroth

Annealing studies on X-ray and neutron irradiated CMOS Monolithic Active Pixel Sensors

Nucl. Instr. \& Meth. In Physics Research A 658 (2011) 133

[6] M. Doering et al.

Radiation tolerance of a column parallel CMOS sensor with high resistivity epitaxial layer

$12^{\text {th }}$ International Workshop on Radiation Imaging Detectors, July $11^{\text {th }}-15^{\text {th }} 2010$ Cambridge, U.K.

NAA

[7] Neutron Activation Analysis http://www.rcm.tum.de/index.php?id=65\&L=1

[8] X. Li, Ch. Lierse von Gostomski

Applications of $k_{0}$ NAA at FRM II with high $f$ values

J. Radioanal. Nucl. Chem. 300 (2014) 457

PGAA

[9] Prompt $\gamma$ Activation Analysis http://www.mlz-garching.de/pgaa

[10] Zsolt Revay, Tamas Belgya

in Handbook of Prompt $\gamma$ Activation Analysis, ed. By Gabor Molnar

Springer Verlag (2004) ISBN 978-0-387-23359-8

[11] Z. Revay, P. Kudejeva, K. Kleszcz, S. Söllradl, Ch. Genreith

In-beam activation analysis facility at MLZ, Garching

Nucl. Inst. \& Meth. A, accepted for publication (2015)

On-line real-time neutron elemental analysis

[12] C. S. Lim

Recent developments in neutron-induced gamma activation for on-line multielemental analysis in industry

Journal of Radioanalytical and Nuclear Chemistry 262 (2004) 525

[13] C. S. Lim, B. D. Sowerby

On-line bulk elemental analysis in the resource industries using neutron-gamma techniques Journal of Radioanalytical and Nuclear Chemistry 264 (2005) 15

FRM II + MLZ-Garching

[14] Forschungsneutronenquelle Heinz Maier-Leibnitz (FRM II) www . frm2 . tum . de

[15] Heinz Maier-Leibnitz Zentrum www .mlz-garching.de

Si-doping

[16] H. Gerstenberg, X. Li, I. Neuhaus

Silicon doping at FRM II

Transactions RRFM 2009, Vienna 22. - 25. March 2009

[17] Xilei Lim, R. Henkelmann, A. Türler, H. Gerstenberg, F. De Corte

Neutron flux parameters at irradiation positions in the new research reactor FRM II

Nucl. Inst. \& Meth. A 564 (2006) 641

[18] J. Hampel, F. M. Boldt, H. Gerstenberg, G. Hampel, J. V. Kratz, S. Reber, N. Wiehl

Fast determination of impurities in metallical grade silicon for photovoltaics by instrumental neutron activation analysis

Applied Radiation and Isopotes 69 (2011) 1365 
Chemisorption

[19] M. W. Chase

NIST-JANAF Themochemical tables, Fourth Edition

J. Phys. Chem. Ref. Data, Monograph 9 (1998) 1-1951

[20] B. Bogdanovic, M. Schwickardi

Ti-doped alkali metal aluminium hydrides as potential novel reversible hydrogen storage material J. Alloys \& Compd. 253 (1997) 1

[21] P. Mauron, F. Buchter, O. Friedrichs, A. Remhof, M. Bielmann, C. N. Zwicky, A. Zuttel

Stability and reversibility of $\mathrm{LiBH}_{4}$

J. Phys. Chem. B 112 (2008) 906

[22] G. Barkhordarian, T. R. Jensen, S. Doppiu, U. Bösenberg, A. Borgschulte, R. Gremaud, Y. Cerenius, M. Dornheim, T. Klassen, R. Bormann

Formation of $\mathrm{Ca}\left(\mathrm{BH}_{4}\right)_{2}$ from Hydrogenation of $\mathrm{CaH}_{2}+\mathrm{MgB}_{2}$ Composite

J. Phys. Chem. C 112 (2008) 2743

[23] M. J. V. Setten, G. A. D. Wijs, M. Fichtner, G. Brocks

A Density Functional Study of $\alpha-\mathrm{Mg}\left(\mathrm{BH}_{4}\right)_{2}$ Chemistry of Materials

Chemistry of Materials, 20(15), (2008) 4952-4956

[24] T. Matsunaga, F. Buchter, P. Mauron, M. Bielman, Y. Nakamori, S. Orimo, N. Ohba, K. Miwa,

S. Towata, A. Zuttel

Hydrogen storage properties of $\mathrm{Mg}\left[\mathrm{BH}_{4}\right]_{2}$

J. Alloys Compd., 459 (2008) 583

[25] W. Luo, E. Ronnebro

Towards a viable hydrogen storage system for transportation application

J. Alloys Compd., 404 (2005) 392

[26] F. Dolci, E. Weidner, M. Hoelzel, Th. Hansen, P. Moretto, C. Pistidda, M. Brunelli, M. Fichtner, W. Lohstroh

In-situ diffraction of magnesium amide/lithium hydride stoichiometric mixtures with lithium hydride excess

Int. J. of Hydrogen Energy 35 (2010) 5448

[27] D. Blanchard, M. D. Riktor, J. B. Maronsson, H. S. Jacobsen et al.

Hydrogen Rotational and Translational Diffusion in Calcium Borohydride from Quasielastic Neutron Scattering and DFT Calculations

J. Phys. Chem. C 114 (2010) 20249

[28] Jianhiang Hu, E. Weidner, M. Hoelzel, M. Fichtner

Functions of $\mathrm{LiBH}_{4}$ in the hydrogen sorption reactions of the $2 \mathrm{LiH}-\mathrm{Mg}\left(\mathrm{NH}_{2}\right)_{2}$ system

Dalton Trans. 39 (2010) 9100

[29] D. Blanchard, et al.

Hindered Rotational Energy Barriers of $\mathrm{BH}_{4}^{-}$Tetrahedra in $\beta-\mathrm{Mg}\left(\mathrm{BH}_{4}\right)_{2}$ from Quasielastic Neutron Scattering and DFT Calculations

J. Phys. Chem. C 116 (2012) 2013

[30] C. Pistidda, D. Pottmaier, F. Karimi, et al.

Effect of $\mathrm{NaH} / \mathrm{MgB}_{2}$ ration on the hydrogen absorption kinetics of the system $\mathrm{NaH}+\mathrm{MgB}_{2}$ Int. J. of Hydrogen Energy 39 (2014) 5030

Physisorption

[31] P. D. C. Dietzel, P. A. Georgiev, J. Eckert, R. Blom, T. Stässle, T. Unruh

Interaction of hydrogen with accessible metal sites in the metal-organic frameworks $\mathrm{M}_{2}$ (dhtp) (CPO-27-M; $\mathrm{M}=\mathrm{Ni}$, Co, $\mathrm{Mg}$ )

Chem. Comm. 46 (2010) 4962 
[32] T. Pham, K. A. Forrest, J. Eckert, et al.

Investigating the Gas Sorption Mechanism in an rht Metal-Organic Framework through Computational Studies

J. Phys. Chem. C 118 (2014) 439

[33] P. Nugent, T. Pham, K. McLaughlin, P. A. Gregoriev, W. Lohstroh, J. P. Embs, M. J. Zaworotko, B. Space, J. Eckert

Dramatic effect of pore size reduction on the dynamics of hydrogen adsorbed in metal-organic materials

J. Mater. Chem. A 2 (2014) 13884

[34] T. Pham, K. A. Forrest, P. A. Gregoriev, W. Lohstroh, Dong-Xu Xue, A. Hogan, M. Eddaoudi, B. Space, J. Eckert

A high rotational barrier for physisorbed hydrogen in an FCU-metal-organic framework Chem. Commun. 50 (2014) 14109

$\mathrm{H}$ in tank

[35] Ł. Gondek, N.B. Selvaraj, J. Czub, H. Figiel, D. Chapelle, N. Kardjilov, A. Hilger, I. Manke Imaging of an operating $\mathrm{LaNi}_{4.8} \mathrm{Al}_{0.2}$-based hydrogen storage container International Journal of Hydrogen Energy 36 (2011) 9751

[36] J. M. Bellosta von Colbe, O. Metz, G. Lozano, P. Panzas, et al.

Behavior of scaled up sodium alanate hydrogen storage tanks during sorption International Journal of Hydrogen Energy 37 (2012) 2807

[37] J. M. Bellosta von Colbe, G. Lozano, O. Metz, Th. Bücherl, R. Bormann, Th. Klassen Design, sorption behavior and energy management in a sodium alanate-based lightweight hydrogen storage tank

International Journal of Hydrogen Energy 40 (2015) 2984

Batteries inside

[38] L. G. Butler, B. Schillinger, K. Ham, T. A. Dobbins, Ping Liu, J. Vajo

Neutron imaging of a commercial Li-ion battery during discharge: Application of monochromatic imaging and polychromatic dynamic tomography

Nucl. Instr. \& Meth. in Physics Research A 651 (2011) 320

[39] A. Senyshyn, M. J. Mühlbauer, K. Nikolowski, T. Pirling, H. Ehrenberg

In operando neutron scattering studies on Li-ion batteries

J. of Power Sources 203 (2012) 126

[40] L. G. Butler, E. H. Lehmann, B. Schillinger

Neutron radiography, tomography, and diffraction of commercial lithium-ion polymer batteries Physics Procedia 43 (2013) 331, 7th International Topical Meeting on Neutron Radiography

[41] A. Senyshyn, M. J. Mühlbauer, O. Dolotko, M. Hofmann, T. Pirling, H. Ehrenberg Spatially resolved in operando neutron scattering studies on Li-ion batteries J. of Power Sources 245 (2014) 678

[42] A. Senyshyn, O. Dolotko, M. J. Mühlbauer, K. Nikolowski, H. Fuess, H. Ehrenberg Lithium Intercalation into Graphitic Carbons Revisited: Experimental Evidence for Twisted Bilayer Behavior

Journal of The Electrochemical Society 160 (2013) A3198

[43] A. Senyshyn, M.J. Mühlbauer, O. Dolotko, H. Ehrenberg

Low-temperature performance of Li-ion batteries: The behavior of lithiated graphite

J. of Power Sources 282 (2015) 235

[44] O. Dolotko, A. Senyshyn, M. J. Mühlbauer, K. Nikolowski, F. Scheiba, H. Ehrenberg

Fatigue Process in Li-Ion Cells: An In Situ Combined Neutron Diffraction and Electrochemical Study

Journal of The Electrochemical Society 2159 (2012) A2082

01001-p.23 
[45] O. Dolotko, A. Senyshyn, M.J. Mühlbauer, K. Nikolowski, H. Ehrenberg Understanding structural changes in NMC Li-ion cells by in situ neutron diffraction J. of Power Sources 255 (2014) 197-203

[46] A. Senyshyn, M.J. Mühlbauer, O. Dolotko, M. Hofmann, H. Ehrenberg Homogeneity of lithium distribution in cylinder-type Li-ion batteries Scientific Reports (2015) submitted

[47] V. Zinth, Chr. von Lüders, M Hofmann, J Hattendorff, I. Buchberger, S. Erhard, J. RebeloKornmeier, A. Jossen, R Gilles

Lithium plating in Lithium ion batteries at sub-ambient temperatures investigated by in-situ neutron diffraction

J. of Power Sources 271 (2014) 152

[48] I. Buchberger, S. Seidlmayer, P. Kudejova J. Hattendorff, J. Schuster, V. Zinth, R. Gilles, H. A. Gasteiger

Anodic transition metal deposition (Ni, Mn, Co) investigated by Prompt $\gamma$ Activation Analysis (PGAA)

Batterietagung 2014, Aachen, 27. - 29. 04. 2014

[49] I. Buchberger, S. Seidlmayer, J. Hattendorff, R. Gilles, P. Kudejova, H. A. Gasteiger

Aging studies on $\mathrm{LiNi}_{1 / 3} \mathrm{Mn}_{1 / 3} \mathrm{Co}_{1 / 3} \mathrm{O}_{2}$ Graphite cells combining XRD, PGAA and electrochemistry

Journal of The Electrochemical Society, (2015) submitted

[50] S. Seidlmayer, J. Hattendorff, I. Buchberger, L. Karge, H. A. Gasteiger, R. Gilles

In Operando Small-Angle Neutron Scattering (SANS) on Li-Ion Batteries

Journal of The Electrochemical Society 162 (2015) A3116

[51] D. Mikhailova, A. Thomas, S. Oswald, W. Gruner, N.N. Bramnik, A. A. Tsirlin,

D. M. Trots, A. Senyshyn, J. Eckert, H. Ehrenberg

Structural Changes in the $\mathrm{LiCrMnO}_{4}$ Cathode Material during Electrochemical Li Extraction and Insertion

Journal of The Electrochemical Society 160 (2013) A3089

[52] N. Paul, J. Brumbarov, A. Paul, Ying Chen, J-F. Moulin, P. Müller-Buschbaum, J. KunzeLiebhäuser, R. Gilles

GISAXS and TOF-GISANS studies on surfaces and depth morphology of self-organized $\mathrm{TiO}_{2}$ nanotube arrays: model anode material in Li-ion batteries

J. Appl. Cryst. 48 (2015) 444

[53] M. Hofmann, R. Gilles, Y. Gao, J. T. Rijssenbeek, M. J. Mühlbauer,

Spatially Resolved Phase Analysis in Sodium Metal Halide Batteries: Neutron Diffraction and Tomography

Journal of The Electrochemical Society 159 (2012) A1833

[54] V. Zinth, S. Seidlmayer, N. Zanon, G. Crugnola, M. Schulz, R Gilles, M. Hofmann

In-Situ spatially Resolved Neutron Diffraction of a Sodium Metal Halide Battery

Journal of The Electrochemical Society 162 (2015) A384

Organic solar cells

[55] M. A. Ruderer, R. Meier, L. Porcar, R. Cubitt, P. Müller-Buschbaum

Phase Separation and Molecular Intermixing in Polymer-Fullerene Bulk Heterojunction Thin Films

J. Phys. Chem. Lett., 3 (2012) 683

[56] M. Rawolle, K. Sarkar, M. A. Niedermeier, M. Schindler, P. Lellig, J. S. Gutmann, J.-F. Moulin, M. Haese-Seiller, A. S. Wochnik, C. Scheu, P. Müller-Buschbaum 
Infiltration of Polymer Hole-Conductor into Mesoporous Titania Structures for Solid-State Dye-Sensitized Solar Cells

ACS Appl. Mater. Interfaces 5 (2013) 719

[57] Shuai Guo, Biye Cao, Weijia Wang, J.-F. Moulin, P. Müller-Buschbaum

Effect of Alcohol Treatment on the Performance of PTB7:PC71BM Bulk Heterojunction Solar Cells

ACS Appl. Mater. Interfaces 7 (2015) 7 (8) 4641

Tailoring internal stresses, a key for light weight alloys

[58] M.T. Hutchings, P.J. Withers, T.M. Holden, T. Lorentzen,

Introduction to the Characterization of Residual Stress by Neutron Diffraction

Taylor \& Francis, London, 2005

[59] M. Schöbel, G. Baumgartner, S. Gerth, J. Bernardi, M. Hofmann

Microstresses and crack formation in AlSi7MgCu and AlSil7Cu4 alloys for engine components,

Acta Materialia 81 (2014) 401

[60] J. Repper, P. Link, M. Hofmann, C. Krempaszky, W. Petry, E. Werner Interphase microstress measurements in IN 718 by cold neutron diffraction Appl. Phys. A 99 (2010) 565

[61] J. Repper, T. Keller, M. Hofmann, C. Krempaszky, W. Petry, E. Werner Neutron Larmor diffraction measurement for materials science

Acta Materiala 58 (2010) 3459

[62] M. Hofmann, W. M. Gan, J. Rebelo-Kornmeier, M. Schöbel Materials science at the diffractometer STRESS-SPEC at FRM II Neutron News 24(3) (2013) 15

[63] M. Reihle, M. Hofmann, U. Wasmuth, W. Volk, H. Hoffmann, W. Petry In-situ strain measurements during casting using neutron diffraction Materials Science Forum 768-769 (2014) 484

[64] U. Wasmuth, L. Meier, M. Hofmann, M. Mühlbauer, V. Stege, H. Hoffmann Optimization of composite castings by means of neutron measurements CIRP Annals - Manufacturing Technology 57 (2008) 579

[65] M. Reihle

Entstehung und Ausprägung von Eigenspannungen in Verbundgussteilen PhD Thesis TUM 2015

[66] M. Schöbel, H.P. Degischer, S. Vaucher, M. Hofmann, P. Cloetens Reinforcement architectures and thermal fatigue in diamond particle-reinforced aluminum Acta Materialia 58 (2010) 6421

Medicine

[67] http://www.frm2.tum.de/en/industry-medicine/radioisotope-production/ lutetium-177/

[68] Tobias Hollmer Development of a PVD-based manufacturing process of monolithic LEU irradiation targets for 99Mo production

$\mathrm{PhD}$ thesis, TUM, 2015

[69] The Supply of Medical Radioisotopes: The Path to Reliability ISBN-978-92-64-99164-4, OECD 2011,

[70] A.Bockisch, F. Grünwald, J. Kotzerke Radionuklidengpass: Ursachen und Lehren Nuklearmedizin 48 (2009) 55 
[71] C. Müller, H. Gerstenberg, A. Röhrmoser, A. Kastenmüller, M. Giourges, G. Haas, P. Jüttner Mo-99 Production at FRM II - Status of the Project

Transactions RRFM 2015, Bucharest 19. - 23. April 2015

[72] B. Loeper-Kabasakal, A. Posch, T. Auberger, F.M. Wagner, S. Kampfer, P. Kneschaurek, W. Petry, P. Lukas, M. Molls

Fission neutron therapy at FRM II: Indications and first results

Radiation Measurements 45 (2010) 1436

Alternatives to ${ }^{3} \mathrm{He}$ detectors

[73] G. Nowak, M. Störmer, H.-W. Becker, C. Horstmann, R. Kampmann, D. Höche, M. Haese-Seiller, J.-F. Moulin, M. Pomm, C. Randau, U. Lorenz, R. Hall-Wilton, M. Müller,

A. Schreyer

Boron carbide coatings for neutron detection probed by $x$-rays, ions, and neutrons to determine thin film quality

J. of Appl. Physics 117 (2015) 034901-13

[74] C. Högl und J. Birch, K. Andersen et al.

B4C thin films for neutron detection

J. Appl. Phys. 111(2012) 104908 